\title{
?1
}

TI 2019-075/VIII

Tinbergen Institute Discussion Paper

\section{A World Divided: Refugee Centers, House Prices, and Household Preferences}

Martijn Dröes ${ }^{1}$

Hans R.A. Koster ${ }^{2}$

${ }^{1}$ Universiteit van Amsterdam

${ }^{2}$ Vrije Universiteit Amsterdam 
Tinbergen Institute is the graduate school and research institute in economics of Erasmus University Rotterdam, the University of Amsterdam and VU University Amsterdam.

Contact: discussionpapers@tinbergen.nl

More TI discussion papers can be downloaded at https://www.tinbergen.nl

Tinbergen Institute has two locations:

Tinbergen Institute Amsterdam

Gustav Mahlerplein 117

1082 MS Amsterdam

The Netherlands

Tel.: +31(0)205984580

Tinbergen Institute Rotterdam

Burg. Oudlaan 50

3062 PA Rotterdam

The Netherlands

Tel.: +31(0)10408 8900 


\title{
A World Divided:
}

\section{Refugee Centers, House Prices, and Household Preferences*}

\author{
Martijn I. Dröes ${ }^{\dagger} \quad$ Hans R.A. Koster ${ }^{\ddagger}$
}

1 November 2019

\begin{abstract}
Abstract - The number of refugees around the world has increased substantially in the last decade. To cope with refugee flows, many countries have built refugee centers (RCs) for refugees to await the outcome of their asylum procedure. The opening of such centers often leads to considerable opposition from the local population. Using detailed housing transactions data from the Netherlands over the period 1990-2015, we examine locals' attitudes towards immigration by investigating households' willingness to pay (WTP) to avoid living near RCs. Comparing the price developments of opened RCs and those that are planned, we show that the opening of an RC decreases house prices within $2 \mathrm{~km}$ by $3-6 \%$. Using micro-data on home buyers' characteristics and employing a non-parametric hedonic pricing method, we identify households' individual preferences. We show that attitudes of higher income households towards RCs tend to be more negative, while those of foreign-born households are more positive. The WTP is also more negative for larger RCs. These results imply that when opening RCs, it is advisable to keep them relatively small and locate them in more ethnically diverse areas.
\end{abstract}

Keywords - immigration, house prices, refugee centers, household preferences.

JEL codes - E02, O18, R31.

\footnotetext{
${ }^{*}$ We thank Wolter Hassink, Dorinth van Dijk, Jos van Ommeren, Wouter Vermeulen, and seminar participants at UEA 2019 in Amsterdam, BZK/UU seminar 2019, and the UvA Research Day 2018 for useful comments. We thank Boris Velthuijs for valuable research assistance.

${ }^{\dagger}$ Corresponding author. Amsterdam Business School, Faculty of Economics and Business, University of Amsterdam, Plantage Muidergracht 12, 1018 TV Amsterdam, e-mail: m.i.droes@uva.nl. Martijn is also affiliated to the Amsterdam School of Real Estate (ASRE) and the Tinbergen Institute.

${ }^{\ddagger}$ Department of Spatial Economics, Vrije Universiteit Amsterdam, De Boelelaan 1105, 1081 HV Amsterdam, email: h.koster@vu.nl. Hans is also research fellow at the National Research University, Higher School of Economics in St. Petersburg and the Tinbergen Institute, and affiliated to the Centre for Economic Policy Research.
} 


\section{Introduction}

According to the United Nations Refugee Agency UNHCR there are currently a record number of 70.8 million forcibly displaced persons around the globe, of which 25.9 million are refugees (UNHCR 2019). Refugee flows have a multitude of underlying causes such as wars, famines, and economic deprivation. For example, the European Union witnessed a sharp increase in the number of asylum applications from about 300 thousand in 2012 to 1.3 million in 2015 due to the war in Syria. Although the influx of refugees to Europe has decreased since due to the deal between Turkey and the EU, immigration remains high on the political agenda of many Western countries. When refugees come to the EU they have to be housed to await the outcome of their asylum procedure. Some of them stay in large camps at the point where they entered the European Union (i.e. Greece, Italy, Spain), but there are also a considerable amount of refugees that are housed in dedicated refugee centers (RCs) within European Union member states.

The increasing immigration flows in the last decade go hand in hand with an increasing popularity of populist, anti-migration, political parties that aim to limit the number of newcomers (Ivarsflaten 2008). Hence, it is not too surprising to see that the opening of an RC, or even the plans to open one, can lead to substantial local opposition. ${ }^{1}$ This has led to a sharp division in opinions whether and where new RCs are supposed to be opened.

The main aim of this paper is to estimate the local residents' attitudes towards immigration by examining to what extent households are willing to pay not to live close to a refugee center. We do so by examining the effect of the opening of RCs on house prices in the near vicinity of an RC. Given the considerable amount of anecdotal evidence about opposition against the opening of RCs, we would expect this effect, on average, to be negative. An important question, however, is to what extent this effect varies across types of refugee centers/location, the local population, and time. Insights in the attitudes of locals towards immigration may help to better understand where there might be local support for refugee centers and, thus, where those centers should be placed.

This paper uses a detailed dataset containing information on about 2.6 million housing trans-

\footnotetext{
${ }^{1}$ There have been many large-scale demonstrations in places where RCs were planned (see e.g. Toonen 2015, Volkskrant 2016, DeStem 2017, De Stentor 2017). In several cases these demonstrations led to fights between the police and protesters (see e.g. Algemeen Dagblad 2016, Bakker 2016).
} 
actions covering the whole of the Netherlands between 1990-2015. Besides transaction prices, the dataset includes information on list prices, the time on market, and an extensive set of housing attributes. A unique feature is that we also employ individual information about the local population living near an RC on income, household composition and whether the person is foreign-born.

The first official RC was opened in 1987. RCs seem to be fairly evenly distributed across the country. The Duranton \& Overman (2005) measure for spatial concentration shows that the spatial distribution of RCs in the Netherlands is random. Nevertheless, a concern is still that RCs may be opened in locations that have lower prices. RCs may for example be opened in locations where the available land is cheaper. Alternatively, RCs may be disproportionately opened in ethnically more diverse locations where the opposition is thought to be less severe.

To address the potential issue of non-random placement we compare the results of several different approaches. First, using a difference-in-differences methodology, house price changes within $2 \mathrm{~km}$ of a realized refugee center are compared to areas where RCs were planned to be opened somewhere after 2015 but were canceled. Second, we estimate the treatment effect by conditioning on locations that have received an RC during the study period. That is, we exploit the variation in the opening date of RCs. ${ }^{2}$ We consider this to be baseline estimate. Third, we use the existing road network to create (100m wide) travel corridors between RCs and the nearest shopping area. The idea is supported by anecdotal evidence that exposure to refugees is concentrated inside these corridors as refugees often visit a local shopping center to buy products and for recreational purposes (Kuppens et al. 2017). We utilize this additional information to estimate the treatment effect using a triple-differences approach. This approach should address any concerns related to a possible non-random placement of RCs.

The average effect of RCs on house prices may give little insight into the distribution of attitudes towards immigrants and does not necessarily correspond to underlying householdspecific willingness to pay parameters (WTP). Rather than just presenting reduced-form estimates, our paper applies a structural two-step non-parametric hedonic pricing method in line with Ekeland et al. (2004) and Bajari \& Benkard (2005), which allows us to measure structural

\footnotetext{
${ }^{2}$ In a standard difference-in-differences model this would not be possible as there is no variation in the timing of treatment.
} 
variation in the individual households' willingness to pay. We address the issue that the WTP for RCs is not point-identified because the variable of interest (the presence of an RC) is dichotomous (see Bajari \& Kahn 2005). We make use of a suggestion by Ekeland et al. (2004) to address simultaneity problems in the second stage, by instrumenting housing attributes with their expected values conditional on household characteristics. The identifying assumption is based on the idea that the hedonic price function is inherently nonlinear.

Our results show that the opening of a refugee center decreases house prices within a $2 \mathrm{~km}$ radius by $3-6 \%$ on average, which is economically sizable. ${ }^{3}$ The statistical evidence suggests that the effect is confined to $2 \mathrm{~km}$. The effect is still there 10 years after the opening of a refugee center, hence the effect is permanent. Closing a refugee center has about the same, but positive, effect on house prices. The results are robust to using a triple-differences approach based on $100 \mathrm{~m}$ wide corridors between refugee centers and the nearest shopping street, which suggests that the effect may not be equidirectional.

Further results indicate that there is considerable heterogeneity in the WTP of households. The median WTP after the opening of a refugee center is about $-€ 16$ thousand. About $6 \%$ of the households have a positive willingness to pay, although this is statistically insignificant in most cases. Households are willing to pay $€ 3$ thousand less for a 100 person increase in the capacity of an RC. In addition, a standard deviation increase in the annual disposable income (about $€ 23.5$ thousand) leads to a further reduction of $€ 1000$ in WTP. Non-western foreign-born persons seem to have a more positive willingness to pay of $€ 7$ thousand. Hence, our findings suggest that attitudes towards immigrants are heterogeneous among the population. Using the heterogeneous WTP estimates we perform a back-of-the-envelope calculation to infer the type and location where RCs should be placed. We find that the best strategy is to build small RCs in ethnically diverse areas. This is in contrast to current practice where many rather large RCs are opened in rural areas that are not very ethnically diverse.

To provide further support for the results on housing prices, in Appendix E we examine whether there is an effect of RCs on the subjective well-being of the population within the local neighborhood. We focus on such measures as residential satisfaction, intention to move and

\footnotetext{
${ }^{3}$ Our preferred baseline estimate is essentially $6 \%(-5.8 \%)$, while the triple-differences approach $(-2.8 \%)$ defines the lower bound estimate of $3 \%$.
} 
indicators on nuisance and the feeling of safety. We also have information on unemployment and the amount of hours worked. We show that the probability to move and the probability to experience dissatisfaction and nuisance increase when an RC is opened. These effects seem in line with the hedonic price analyses. By contrast, we do not find effects on feeling more unsafe and show that there is a decrease in local unemployment where an $\mathrm{RC}$ opens.

Our paper contributes to several strands of literature. First, we add to the literature on the effects of immigration on the local economy. Sizable immigration flows are suspected to have impact on employment opportunities of natives. However, evidence regarding this issue is quite mixed. Borjas (2003) for example finds that immigration lowers the wage of competing workers, while Dustmann et al. (2005) find no strong evidence that immigration has an effect on aggregate employment, participation, unemployment and wages. By contrast, Docquier et al. (2014) find that immigration has a positive effect on the wages of less educated natives (in the OECD) and it may increase average wages for natives. More recent evidence shows that Syrian refugees may lead to openings of firms and growth in gross profits in Turkey (Akgündüz et al. 2018).

The impact of immigration on the housing market is largely unstudied. ${ }^{4}$ The literature so far mainly concentrates on the location choices of immigrants themselves. Åslund (2005) for example shows that migrants to Sweden are attracted to regions with a high representation from the individual's birth country and a large immigrant population. Sorting in areas with many peers appears to improve labor market outcomes for less skilled immigrants (Edin et al. 2003). Forrest et al. (2013) show that most refugees in Australia resettled into the private rental market when leaving an $\mathrm{RC}$ and were satisfied with their housing situation. Using data at the district level in the UK, Lastrapes \& Lebesmuehlbacher (2018) show that the number of asylum seekers housed in dispersal accommodation has a (small) negative impact on local house prices, particularly low priced housing. Their data, unfortunately, does not contain information on property size or owner characteristics.

Tumen (2016) also measures the impact of refugees on the housing market, by using variation provided by the recent inflow of Syrian immigrants into Turkey. He shows that refugee inflows

\footnotetext{
${ }^{4}$ Daams et al. (2019) investigate the impact of RCs on house prices in the Netherlands using a limited sample of transactions between 2009-2017. While the setting is similar, Daams et al. (2019) do only partly address the potential non-random placement of RCs over space and time, which appears to have significant implications for the estimated coefficients. They also show some evidence of heterogeneity in the effects of RCs, but do not link these to characteristics (and perception) of the local population.
} 
increased the rents of higher quality housing units, while there is no effect on lower quality units. Dustmann \& Preston (2007) find strong evidence that racial or cultural prejudice is an important determinant of attitudes towards immigration. Our paper contributes to the literature by using housing prices to measure attitudes of the local population towards immigrants. Rather than measuring average effects, we pay specific attention to the heterogeneity in attitudes towards RCs and we show some effects regarding the perception of RCs with respect to feeling unsafe and experiencing nuisance.

Second, we contribute to a growing literature on hedonic pricing aiming to identify households' preferences. To identify structural parameters in hedonic models, rather than only implicit prices, Rosen (1974) suggests a two-step procedure. However, it has been shown that preference parameters are only identified given arbitrary functional form assumptions, such as the assumption of homogeneous preferences (Brown \& Rosen 1982, Ekeland et al. 2002). Ekeland et al. (2004), however, argue that the marginal willingness to pay is generically a non-linear function of household's characteristics and housing attributes. This non-linearity provides information that rules out collinearity between an endogenously-chosen characteristic and its marginal willingness to pay and enables identification of structural parameters in a single market, given the assumption that marginal utility is additive and, importantly, that unobserved attributes of individuals (e.g. ability, race) are independent of observed attributes of individuals. Bajari \& Benkard (2005) and Bajari \& Kahn (2005) consider identification of preferences in a hedonic price model in the presence of heterogeneity in households' preferences. They show that, given a linear utility function, housing preference parameters are identified. However, the assumption of linear utility functions is quite restrictive. Instead, we follow Ekeland et al. (2004) and use a utility function that allows for interactions between housing attributes and household characteristics. We combine this approach with an insight of Bajari \& Kahn (2005), who shows that housing preferences can be identified, even though the variable of interest is dichotomous. ${ }^{5}$

The remainder of this paper is structured as follows. In Section 2 we discuss the history and

\footnotetext{
${ }^{5}$ Recent papers by Bishop \& Timmins (2018) and Bishop \& Timmins (2019) show alternative ways to estimate preferences. Bishop \& Timmins (2018) use panel data on houses and individuals to estimate the demand for air quality. They observe households multiple times and use the variation over time, assuming that preferences do not change over time. Given that we only include households and transactions near RCs, the approach relying on repeated observations is not feasible. Alternatively, Bishop \& Timmins (2019) use a maximum likelihood approach to estimate preferences for violent crimes. This approach, however, is only applicable for continuously distributed housing attributes, while the placement of an RC is dichotomous.
} 
political context regarding refugees. Section 3 introduces the data, followed by the research framework in Section 4. Section 5 reports the regression results. Section 6 provides a conclusion and discussion.

\section{International, European, and national policy on refugees}

Directly after World War II there were many 'displaced' persons in Europe and around the globe. The term refugee was formally defined in the 1951 Refugee Convention. This treaty, originally signed by 144 states, only arranged the status of refugees as a result of events before 1951 and mainly focused on European refugees. In 1967, this treaty was broadened to include all persons. Currently, the treaty is ratified by 145 states.

Although the European Union has a long history in terms of migration policy (for an overview see, Obdeijn \& Schrover 2009), the 1990 Dublin Convention marked one of the first attempts to improve the immigration process. The central aim was to reduce the number of multi-country applications by asylum seekers by having the application being processed by the first country of entry. It took until 1997 before the treaty was signed. One of the main problems of the treaty was that also in case of irregular entry (e.g. by land or sea) the first country of entry remains responsible for the application procedure. This has led to an unequal burden on some countries at the border of the European Union, which created so called 'hotspots' in Greece and Italy. Therefore, a reallocation scheme was implemented to redistribute the refugees across member states (European Commission 2015).

The 1951 Refugee Convention was ratified by the Dutch government in 1956. In 1965 this led to the Law on Foreigners (in Dutch: Vreemdelingenwet). The responsibility of taking care of the refugees was given to the municipalities. With the increase of the number of refugees (and financial burden) over time, the Dutch government decided to change the regulation. This regulation (in Dutch: Regeling Opvang Asielzoekers) led to the establishment of the first officially dedicated refugee centers in 1987. After that, the government bodies responsible for the asylum procedure became gradually more independent and eventually, in 1994, a law was passed that led to the creation of a separate government institute $(C O A)$ responsible for the processing of refugees including the opening of RCs. Although the exact reasons why an RC is opened at a particular location is rather opaque and subject to negotiations with local municipalities, $C O A$ 


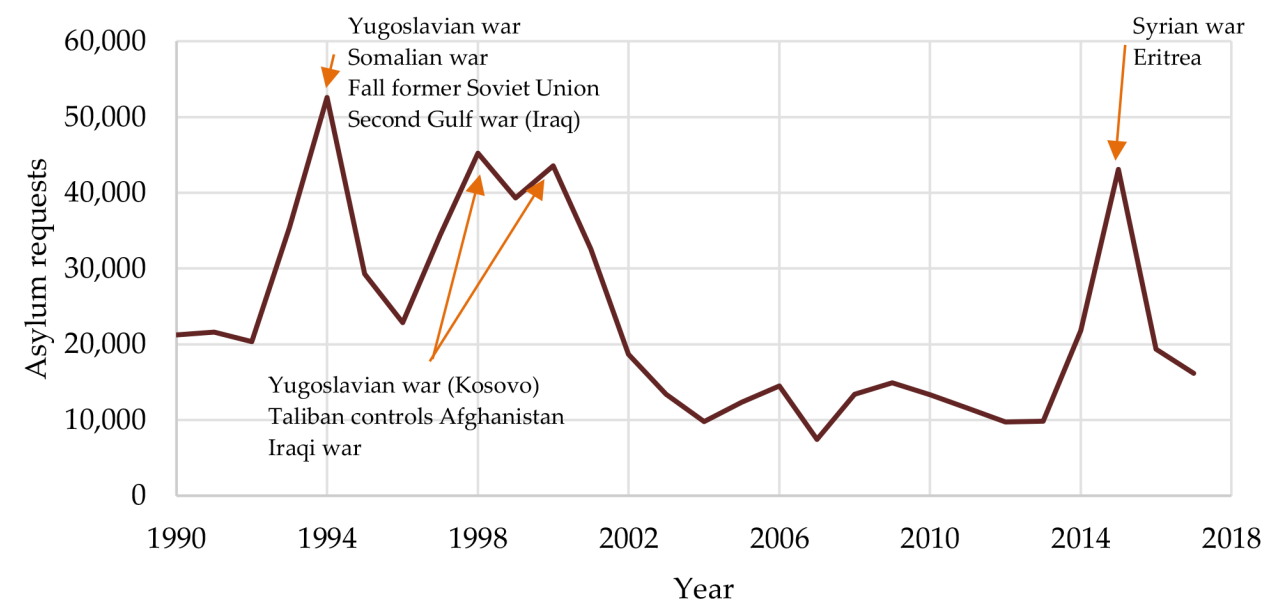

Figure 1 - Inflow of Refugees in the NetherlandS

Notes: This figure shows the number of asylum seekers (first) requests in the Netherlands and some of the underlying causes. Source: Statistics Netherlands.

aims at distributing RCs over different provinces.

The asylum application itself is evaluated by the Immigration and Naturalisation Service and the length of the procedure depends on the probability that an application is successful. By law, a decision should officially be made within 6 months but there have been quite a few cases known where the procedure has taken years, for example due to the possibility to appeal the decision (NRC 2018). If the application is successful the asylum seeker obtains a residence permit and municipalities (depending on their population) have to house these asylum seekers (for a detailed overview see, CBS 2018).

The number of refugees that arrive in the Netherlands has varied considerably over time and there are a variety of underlying causes that explain the inflow of refugees. Figure 1 depicts the number of asylum seeker requests from 1990 until 2017 and shows several distinctive peaks. The peak in 1994 is mainly due to the Yugoslavian civil war, which started in 1992. About $25 \%$ of the refugees coming to the Netherlands in 1994 were from Yugoslavia. Other important categories were Somalians (10\%), but also refugees from the former Soviet Union (9\%) and Iraqi refugees due to the Second Gulf war (5\%). The sudden influx of refugees in 1998 is due to another outburst in the Yugoslavian war (i.e. in Kosovo), and the Taliban taking over control in Afghanistan. Finally, in 2015 the Syrian war led to an unprecedented amount of refugees from one country ( $43 \%$ of the total) but there was also a considerable amount of Eritrean refugees 
$(17 \%)$, fleeing because of political repression.

According to Figure 1 the inflow of refugees and, consequently, the need for capacity to house those refugees is a recurring event and will most likely remain a political and societal challenge in the future.

\section{$3 \quad$ Data and descriptive statistics}

\subsection{Data}

Three main sources of data are combined: housing transactions data, household level data, and data on locations and openings of refugee centers. The housing transactions data are taken from the Dutch Association of Realtors. It covers the period 1990-2015, and captures about $60-70 \%$ of the market. The dataset contains information about the sales price, house size, number of rooms, construction year, type of property (apartment, terraced, semi-detached, detached), presence of garage and garden, whether the property is well maintained, has a central heating system, and is listed as cultural heritage. We also know the exact location as well as the (6-digit) zip code, which covers about 15-20 addresses each. The full dataset contains 2.6 million transactions.

The second dataset is from Statistics Netherlands. We use data from the Sociaal Statistisch Bestand (SSB), which provides basic information on demographic characteristics, such as age, country of birth, and gender. ${ }^{6}$ We only keep individuals that could be part of the working population, that is, who are between 25 and 65 years of age. We aggregate the data to the household level. Furthermore, we use information on household characteristic, such as household size, whether there are children in the household, as well as the marital status of the adults. We link these data to the Integraal Huishoudens Inkomen panel dataset to obtain information on households' disposable income. We matched this data with the housing transactions data to have information on characteristics of the buyer. The household level data is only available as of the year 2000 .

Finally, the third dataset contains the information on Dutch refugee centers. We distinguish between four categories: realized, planned, closed and canceled RCs. Our main database is taken from the website of COA, www.coa.nl, and contains all realized (permanent) refugee centers

\footnotetext{
${ }^{6}$ In contrast to countries like the United States or the United Kingdom, the Netherlands does not undertake censuses to register their population, but the register is constantly updated when people move or when household composition changes.
} 
that were still open in 2015. There are 51 of such centers. We added to this sample 15 refugee centers from www.nrc.nl that were planned to be opened in 2016 and 2017. ${ }^{7}$ Most of them did not open eventually, we refer to those as 'canceled' RCs. Also, based on online sources (e.g. news articles), we hand-collected 10 centers that were opened before 2015 but were closed before this date. For all refugee centers we have the opening date, its capacity (the exact number and allocation of asylum seekers is not publicly known due to privacy considerations), and we know whether the $\mathrm{RC}$ is realized in an existing or new building.

There is anecdotal evidence that exposure to refugees is concentrated in corridors between the $\mathrm{RC}$ and the nearest shopping center, as the refugees walk trough these corridors to the shopping street to obtain clothes, food, and other items (Kuppens et al. 2017). We can use this as additional information to identify the effect of RCs on house prices. To implement this empirically, we create corridors (100m wide) from the $\mathrm{RC}$ to the nearest shopping center (consisting of more than 25 shops). ${ }^{8}$ This is based on the existing road network in 2015. Figure 2 shows an example of such corridors. The average length of a corridor is $1.9 \mathrm{~km}$.

\subsection{Descriptives}

We display the number of refugee centers opened over time in Figure 3. The number of refugee centers increased gradually over time but especially at the end of our sample (from 2011 onwards). We will split the sample into parts to examine whether the marginal effect of RCs has changed over time.

Table 1 shows descriptives for the RCs. On average, the capacity is 532 persons. There is quite a bit of variation: the capacity varies from 100 to 2000. About one-third of the RCs are in newly constructed buildings. This share is somewhat higher for planned RCs (about 50\%). For closed RCs, the average opening spell is 9 years. ${ }^{9}$

Figure 4 depicts the spatial allocation of RCs. They seem to be quite uniformly distributed across space. To check whether this is indeed the case, we compare the observed spatial distribution

\footnotetext{
${ }^{7}$ Specifically, we obtain data on planned locations from https://www.nrc.nl/nieuws/2016/10/14/ groot-deel-van-de-geplande-azcs-komt-er-niet-4828253-a1526722. We double check and complement this data using various sources on the internet.

${ }^{8}$ We obtain data on shopping locations from Locatus, see Koster et al. (2017) for more information.

${ }^{9}$ We focus on permanent RCs. Temporary RCs, i.e. RCs of which it is known that they they are temporary, are often closed within one or two years. Although we lack detailed data on temporary RCs, we do not think this is a major issue because the effects of temporary RCs on housing prices should be an order of magnitude smaller.
} 


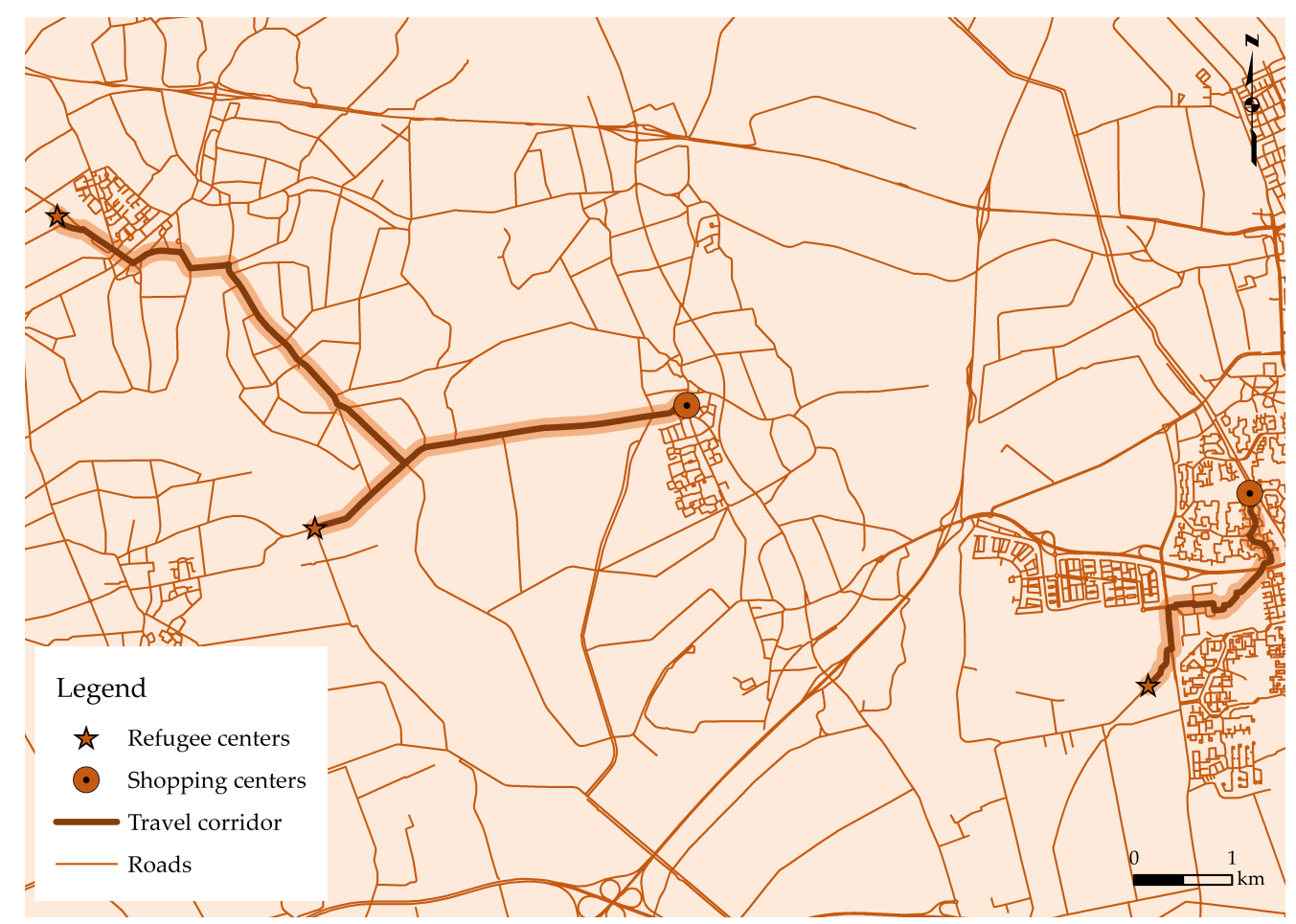

Figure 2 - CORRIDOR BETWEEN REFUGEE CENTERS AND NEAREST SHOPPING STREET

Notes: This figure shows the $100 \mathrm{~m}$ wide corridors between refugee centers and the nearest shopping area with at least 25 shops. The existing road network in 2015 is used to create these corridors.

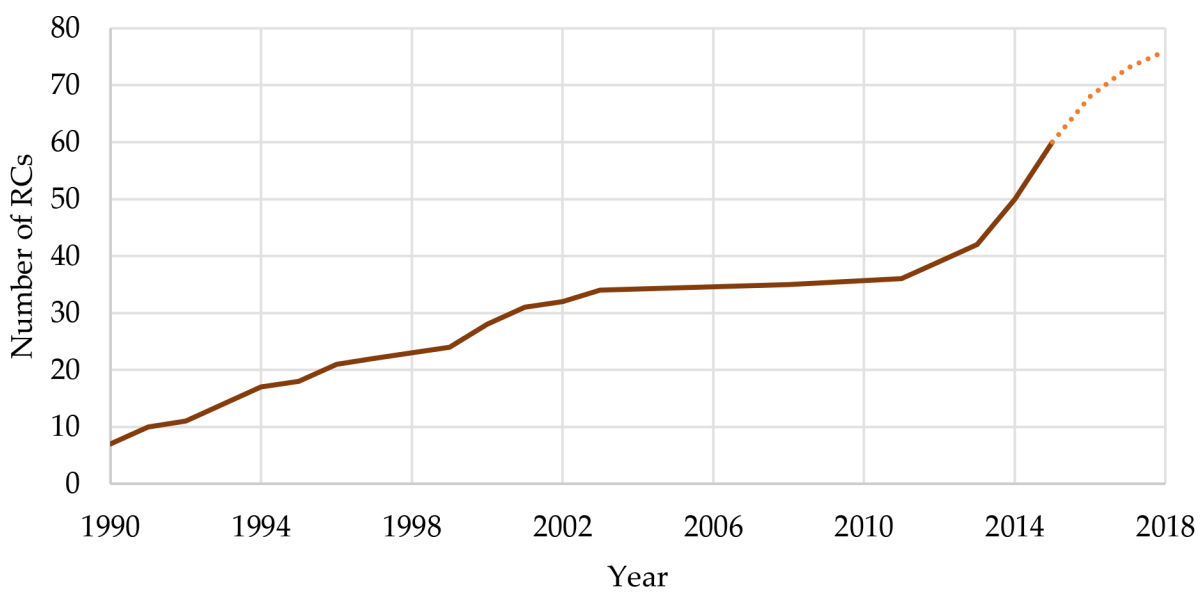

Figure 3 - Number of REFUGEe CENTERS BY OPENING YEAR

Notes: This figure shows the number of opened refugee centers by opening year. After 2015 those are planned opening dates.

of realized, planned, canceled, and closed RCs with a randomly distributed sample using the Duranton \& Overman (2005) measure for spatial concentration. This entails estimating Kernel densities for different distances and investigating whether they deviate significantly from a 


\begin{tabular}{|c|c|c|c|c|c|c|c|c|}
\hline & \multicolumn{2}{|c|}{ Realized } & \multicolumn{2}{|c|}{ Planned } & \multicolumn{2}{|c|}{ Closed } & \multicolumn{2}{|c|}{ Canceled } \\
\hline & $(1)$ & $(2)$ & $(3)$ & $(4)$ & $(5)$ & $(6)$ & $(7)$ & $(8)$ \\
\hline & mean & sd & mean & $\mathrm{sd}$ & mean & sd & mean & sd \\
\hline Refugee center capacity & 532.4 & 322.0 & 496.7 & 136.9 & 413.5 & 221.5 & 434.8 & 173.4 \\
\hline Year of opening refugee center & 2,005 & 10.35 & 2,017 & 0.799 & 1,996 & 6.620 & - & - \\
\hline Year of closure refugee center & - & - & - & - & 2,005 & 3.843 & - & - \\
\hline Construction year of the building & 1,973 & 31.90 & 1,989 & 36.75 & 5,171 & 4,155 & - & - \\
\hline Newly built & 0.314 & 0.469 & 0.533 & 0.516 & 0.100 & 0.316 & - & - \\
\hline
\end{tabular}

randomly generated spatial distribution (for a full description see Appendix B.1). The results of this measure are depicted in Figure 5. Given that the estimated $K$-densities fall well within the $95 \%$ confidence bands, this indeed suggests that the spatial distribution of refugee centers is close to random.

Table 2 contains the descriptive statistics for the house price dataset. The average house price is $€ 203,626$ in the overall sample. Because we have the exact locations of the houses that have been sold and the refugee centers we can calculate for each property the distance to the nearest refugee center. We will use $2 \mathrm{~km}$ as the baseline threshold to estimate the treatment effect but we will report effects also for other thresholds. In total, the treatment group consists of 116,310 houses and 148,553 transactions. About $2.8 \%$ of housing transactions (74,976 observations) are within a $2 \mathrm{~km}$ radius of a refugee center after it has opened (see Table 2). As mentioned, we also estimate the impact of RCs using corridors to the nearest shopping area. As shown in Table 2 only about $0.1 \%$ of the observations are inside corridors after the opening of an RC.

The underlying house price and housing characteristics are somewhat different close to RCs. In Appendix A.1 the housing transactions dataset is split into four categories of refugee centers (realized, closed, planned, and canceled). House prices are high in locations where refugee centers will be or are closed $(€ 226,333)$ and low were they are planned $(€ 181,549)$. Households close to realized refugee centers, however, show an average transaction price (€203, 030), which is very close to that in the full sample. Housing characteristics across the different categories also differ a bit. This highlights that it is potentially important to control for housing characteristics in the regression analyses. ${ }^{10}$ In any case, our identification strategy will address any concerns

\footnotetext{
${ }^{10}$ Not surprisingly, given the size of the dataset, all of the differences in the means across the refugee center categories are statistically significant.
} 


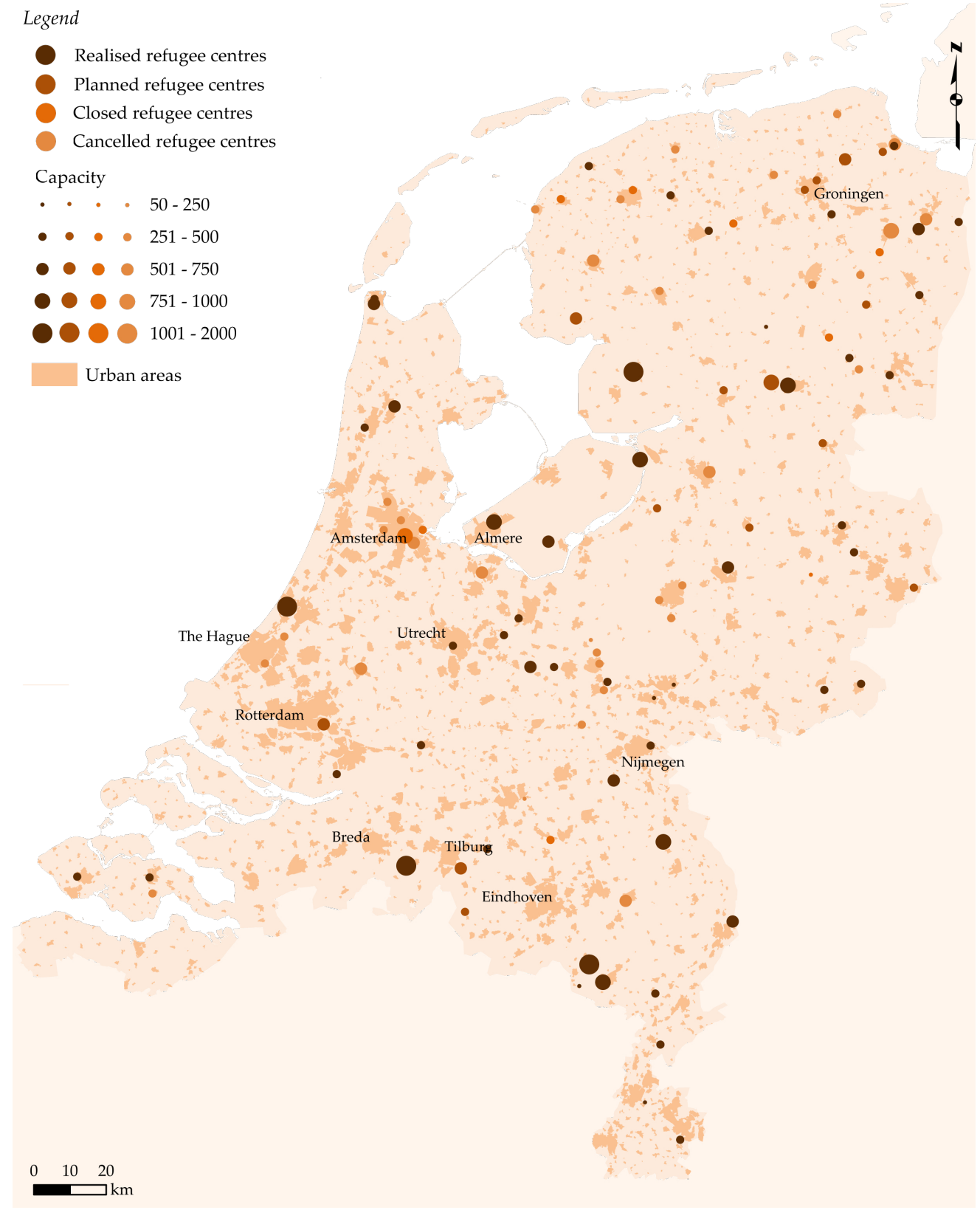

Figure 4 - Spatial distribution of REfugee CEnters

Notes: This figure shows the location and size (capacity in persons) of refugee centers in the Netherlands. The refugee centers are separated into four groups: Those that were realized before 2015 and still present in 2015, those that were planned to be opened after 2015, those that were realized before 2015 and closed somewhere before this date, and centers that we planned to be build after 2015 but were canceled. For the first three categories we have the opening date which we use to measure the effect of refugee centers on house prices.

regarding potential non-random placement.

The descriptive statistics for the matched dataset, containing housing transactions and household characteristics, is reported in Table 3 . We focus on observations within $2 \mathrm{~km}$ of an RC. The 


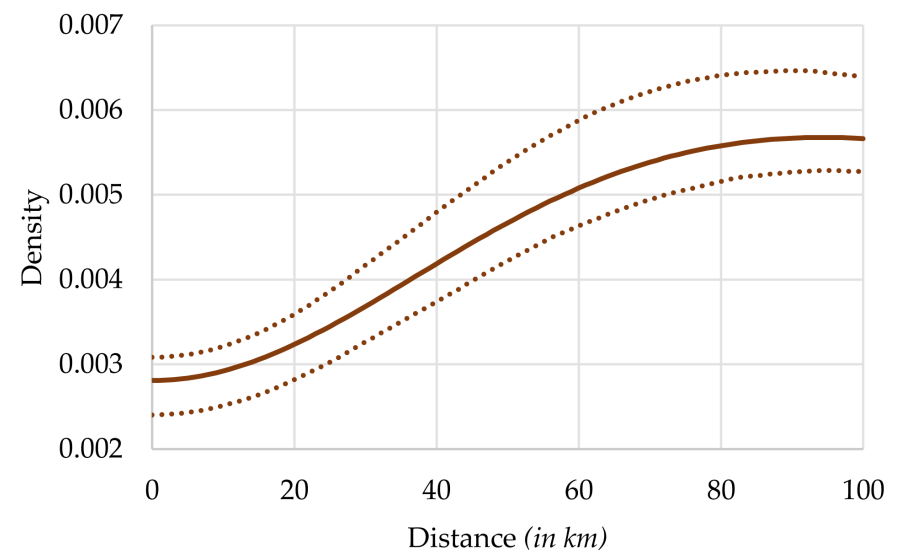

Figure 5 - Spatial concentration of Refugee Center locations

Notes: This figure uses the Duranton \& Overman (2005) measure of comparing spatial distributions to examine whether the actual distribution of refugee center locations deviates from a randomly generated sample of refugee locations. For a detailed explanation, see Appendix B.1.

\begin{tabular}{|c|c|c|c|c|}
\hline & $\begin{array}{l}(1) \\
\text { mean }\end{array}$ & $\begin{array}{c}(2) \\
\text { st.dev. }\end{array}$ & $\begin{array}{l}(3) \\
\min \end{array}$ & $\begin{array}{l}(4) \\
\max \end{array}$ \\
\hline Sales price $(€)$ & 203,626 & 114,657 & 25,000 & $1,000,000$ \\
\hline List price $(€)$ & 216,367 & 124,536 & 22,916 & $1,400,000$ \\
\hline Time on market (days) & 135.1 & 185.7 & 0 & 1,825 \\
\hline Refugee center opened, $<2 \mathrm{~km}$ & 0.0283 & 0.166 & 0 & 1 \\
\hline Within corridor to shopping area & 0.0012 & 0.034 & 0 & 1 \\
\hline Size in $\mathrm{m}^{2}$ & 117.0 & 37.58 & 26 & 250 \\
\hline Number of rooms & 4.336 & 1.330 & 0 & 25 \\
\hline Terraced property & 0.320 & 0.466 & 0 & 1 \\
\hline Semi-detached property & 0.277 & 0.447 & 0 & 1 \\
\hline Detached property & 0.121 & 0.326 & 0 & 1 \\
\hline Property has garage & 0.324 & 0.468 & 0 & 1 \\
\hline Property has garden & 0.973 & 0.161 & 0 & 1 \\
\hline Maintenance state is good & 0.865 & 0.342 & 0 & 1 \\
\hline Property has central heating & 0.894 & 0.308 & 0 & 1 \\
\hline Property is (part of) listed building & 0.00606 & 0.0776 & 0 & 1 \\
\hline
\end{tabular}

\footnotetext{
Notes: The number of observations is 2,649,070. The dataset also includes 6 construction decade indicators which we will use in the regression analysis. Apartments are the reference category for the type of house dummies. The corridors between RCs and shopping areas (> 25 shops) are $100 \mathrm{~m}$ wide and based on the road network in 2015. The corridor indicator is one after a RC gets opened. The sample period is 1990-2015.
}

average house price is somewhat higher than in the full sample (about $12.5 \%$ ) because the data is available as of the year 2000 . The average yearly household disposable income is $€ 35,847$ (with a standard deviation of $€ 23,642$ ). About one-third of the households in our sample are single households and about 5\% are foreign-born. We refer to foreign-born individuals as those that are born in a non-western country, implying that those are born outside of the European 


\begin{tabular}{|c|c|c|c|c|}
\hline & $\begin{array}{c}(1) \\
\text { mean }\end{array}$ & $\begin{array}{l}(2) \\
\text { sd }\end{array}$ & $\begin{array}{l}(3) \\
\min \end{array}$ & $\begin{array}{l}(4) \\
\max \end{array}$ \\
\hline Sales price (in $€$ ) & 228,837 & 118,179 & 32,000 & $1,000,000$ \\
\hline $\mathrm{RC}$ opened $<2 \mathrm{~km}$ & 0.433 & 0.496 & 0 & 1 \\
\hline Capacity of nearest RC & 493.6 & 248.4 & 75 & 1,700 \\
\hline Age of head of the household & 38.58 & 12.12 & 25 & 94 \\
\hline Share of household that is (non-western) foreign-born & 0.0470 & 0.212 & 0 & 1 \\
\hline Disposable income & 35,847 & 23,642 & 6,019 & $1,000,000$ \\
\hline Household size & 2.174 & 1.154 & 1 & 11 \\
\hline Single household & 0.335 & 0.472 & 0 & 1 \\
\hline Single parent with kids & 0.0395 & 0.195 & 0 & 1 \\
\hline Couple & 0.381 & 0.486 & 0 & 1 \\
\hline Couple with kids & 0.244 & 0.430 & 0 & 1 \\
\hline Person is male & 0.692 & 0.462 & 0 & 1 \\
\hline Size of the house (in $m^{2}$ ) & 112.7 & 36.46 & 26 & 250 \\
\hline Number of rooms & 4.243 & 1.363 & 0 & 14 \\
\hline Terraced property & 0.312 & 0.463 & 0 & 1 \\
\hline Semi-detached property & 0.250 & 0.433 & 0 & 1 \\
\hline Detached property & 0.0839 & 0.277 & 0 & 1 \\
\hline Property has garage & 0.282 & 0.450 & 0 & 1 \\
\hline Property has garden & 0.984 & 0.127 & 0 & 1 \\
\hline Maintenance state is good & 0.887 & 0.317 & 0 & 1 \\
\hline Property has central heating & 0.931 & 0.254 & 0 & 1 \\
\hline Property is (part of) listed building & 0.00938 & 0.0964 & 0 & 1 \\
\hline
\end{tabular}

Notes: The number of observations is 57,728 . Because of confidentiality restrictions the minimum and maximum values refer to the $0.01 \%$ and $99.99 \%$ percentile. This implies that we exclude the bottom and top 62 observations. We only include observations within $2 \mathrm{~km}$ of a realised or planned RC. The dataset also includes 6 construction decade indicators which we will use in the regression analysis. The sample period is $2000-2015$.

Union.

\section{Research framework}

\subsection{Reduced-form specification}

\subsubsection{Baseline specification}

We first aim to estimate the treatment effect of refugee centers (RCs) on house prices. In this subsection we explain our identification strategy to measure implicit prices. In the following subsection we extend this framework by using a non-parametric hedonic price approach to identify the individual willingness to pay.

Let $P_{i t}$ be the transaction price of property $i$ sold in year $t$ and $\mathcal{R} \mathcal{C}_{i t}$ be an indicator variable that equals one when an RC has been opened within $\bar{d} \mathrm{~km}$ of the house. We initially assume 
that $\bar{d}=2 \mathrm{~km}$. The equation to be estimated is then:

$$
\log P_{i t}=\beta_{1} \mathcal{R C}_{i t}+\beta_{2} X_{i t}+\lambda_{j}+\lambda_{t}+\epsilon_{i t},
$$

where $X_{i t}$ are a set of housing attributes (e.g. house size, construction year), $\lambda_{j}$ are zip code fixed effects, $\lambda_{t}$ are year and month fixed effects, and $\epsilon_{i t}$ is the error term. Because zip codes are small, this implies that we identify the effects of refugee centers using variation in house prices over time.

We are particularly interested in the parameter $\beta_{1}$ to examine whether there is a negative treatment effect on house prices. We estimate three different versions of equation (1). First, we estimate a standard difference-in-differences (DID) specification using all available data. The before/after opening dummy is absorbed by $\lambda_{t}$ and the control/treatment dummy by $\lambda_{j}$. The DID framework takes into account that RCs may potentially be opened in locations with lower house prices. An important assumption in a DID framework is the parallel trend assumption, which requires that in the absence of the treatment, the difference in prices between the treated and control observations is constant over time.

The main issue with a standard DID approach is that there may be unobserved reasons why an $\mathrm{RC}$ is opened in a particular area, for example in areas where prices are declining. That is, RCs may be disproportionately placed in areas where the is an abundance of cheap space available. Therefore, in a second specification, we only include observations that are either within $2 \mathrm{~km}$ of an actual RC (that is already opened or will be opened in the future) or within $2 \mathrm{~km}$ of RCs that are planned to be opened after 2015 (in 2016, 2017) but were canceled. These latter areas should be comparable in terms of unobserved traits that are potentially correlated with the decision to open an RC.

Using this as control group may be problematic when RCs are canceled non-randomly (e.g. because of public opposition or lack of space). Hence, we therefore employ a third approach were we only use the variation in the opening dates of the eventually realized RCs to identify the treatment effect. In this way, the parallel trend assumption is much less restrictive - as the price trends, conditional on the opening of an RC, between properties near existing RCs and future RCs should be the same. This assumption is violated if the timing of the construction 
of RCs is non-random and occurs primarily in areas where prices are declining relatively. In order to explore this potential issue further, we undertake an event study where we decompose the effect based on the years before and after the opening of an RC. This results in a response function capturing the estimated coefficient for each year before and after opening of an RC and allows us to investigate whether there is a transitory or permanent effect on house prices and whether anticipation effects are important.

We also test whether the choice of a $2 \mathrm{~km}$ impact area is valid. That is, we add dummy variables to estimate the effect at longer distances. If a $2 \mathrm{~km}$ radius is valid, we would expect that the effect beyond $2 \mathrm{~km}$ is statistically insignificant.

\subsubsection{Revisiting identification}

It is possible to question the assumption that the impact of RCs on house prices is equidirectional. As an improvement on uniform treatment areas, we consider effects of RCs to be restricted to corridors. As mentioned, the hypothesis is that the potential nuisance from RCs is concentrated in these corridors as the refugees walk trough these corridors to the nearest shopping district.

We define corridors using the shortest route from each $\mathrm{RC}$ to the nearest shopping center and we choose the corridors to be only $100 \mathrm{~m}$ wide. Using this definition, we estimate:

$$
\log P_{i t}=\beta_{0} \mathcal{R C}_{i t \in \mathcal{C}}+\beta_{2} X_{i t}+\lambda_{j}+\lambda_{t}+\epsilon_{i t},
$$

were $\mathcal{R} \mathcal{C}_{i t \in \mathcal{C}}$ now equals 1 if a transaction is within the corridor and within $2 \mathrm{~km}$ of a realized $\mathrm{RC}$. We use the same three control groups as in the previous analysis: the whole of the Netherlands, corridors near planned but canceled RCs, and areas in which an RC will be placed.

Although using different control groups might alleviate endogeneity concerns, the corridor analysis is still subject to the same possible concern of non-random placement as the analysis based on a circular impact area. To mitigate this issue, we combine both approaches:

$$
\log P_{i t}=\beta_{0} \mathcal{R C}_{i t \in \mathcal{C}}+\beta_{1} \mathcal{R C}_{i t}+\beta_{2} X_{i t}+\lambda_{j}+\lambda_{t}+\epsilon_{i t}
$$

In the above equation we estimate a triple-difference specification where we measure the change 
in prices in corridors within $2 \mathrm{~km}$ of an opened $\mathrm{RC}$ conditional on being within $2 \mathrm{~km}$ of an $\mathrm{RC}$. Hence, $\beta_{0}$ now still captures the treatment effect. When the effect within $2 \mathrm{~km}$ of an $\mathrm{RC}$ is partly capturing some local price trends, this is unlikely to be the case for the difference between the corridor and the other observations within $2 \mathrm{~km}$ of an RC. Note that because the treatment effect may extend beyond the corridor, we may underestimate the treatment effect using this approach. Hence, this estimate can be interpreted as a lower bound estimate. To mitigate this issue we exclude observations between $100 \mathrm{~m}$ and $1 \mathrm{~km}$ from the road towards the shopping center.

In the empirical analysis we also consider additional robustness checks and extensions. For example, we test whether closings have the opposite effect of openings, we obtain the treatment effect using repeat sales, we test the impact on the mark-up (i.e. the difference between the sales prices and list price) and the time on the market, and test whether the effect of RCs on house prices is constant over time.

\subsection{Identifying preference parameters: a non-parametric hedonic price approach}

Having established the average effect, we further explore the heterogeneity in the effect. A considerable literature on hedonic pricing focuses on recovering estimates for marginal changes in characteristics and estimates average effects for the population. It is possible to simply add interaction terms between $\mathcal{R} \mathcal{C}_{i t}$ and the characteristics of a refugee center (like its capacity), as well as household characteristics, and measure the additional effect on marginal prices. However, because the number of potential interactions grow large very quickly, such an approach would suffer from the curse of dimensionality (Yatchew 2003). ${ }^{11}$ In addition, interaction effects do not necessarily identify the underlying preferences (Ekeland et al. 2004). Hence, we go beyond estimating the average marginal effect and aim to recover household-specific willingness to pay (WTP) estimates for RCs. Following Bajari \& Kahn (2005), we regress these WTP on characteristics of RCs and individual characteristics to explain the heterogeneity in WTP across households. We employ a two-step approach.

First, assume that the hedonic price function is given by:

$$
P_{i j t}=\gamma_{1 j}\left(W_{i t}, X_{i t}, Z_{j t}\right) \mathcal{R} \mathcal{C}_{i t}+\gamma_{2 j}\left(W_{i t}, X_{i t}, Z_{j t}\right) X_{i t}+\lambda_{j}+\mu_{t}+\epsilon_{i t} .
$$

\footnotetext{
${ }^{11}$ We show the results of such an analysis in Appendix D.1. The results follow a similar pattern as the non-parametric results but, as mentioned, do not measure any individual variation in the effect.
} 
The implicit prices $\gamma_{1 j}$ and $\gamma_{2 j}$ are flexible functions of RC attributes, $W_{i t}$ (such as capacity and whether it is new built), housing attributes, $X_{i t}$, and household characteristics $Z_{j t}$ (such as age and household composition).

Moreover, the underlying utility function of individual $j$ occupying property $i$ in year $t$ is assumed to be equal to:

$$
U\left(\mathcal{R C}_{i t}, X_{i t}, Z_{j t}\right)=\alpha_{0 j}+\alpha_{1 j} \mathcal{R C}_{i t} W_{i t}+\alpha_{2 j} \mathcal{R C}_{i t} Z_{j t}+\alpha_{3 j} \mathcal{R C}_{i t} X_{i t}+f\left(Z_{j t}\right)+g\left(X_{i t}\right)+C_{j t}
$$

where $\alpha_{0 j}$ is a constant, $\alpha_{1 j}, \alpha_{2 j}$ and $\alpha_{3 j}$ are the preference parameters of interest, and $C_{j t}$ measures other consumption. The functions $f\left(Z_{j t}\right)$ and $g\left(X_{i t}\right)$ determine the level of utility based on household characteristics and housing attributes, respectively. As utility is assumed to be additively separable, these two functions do not play any role in defining the utility maximizing outcome with regard to $\mathcal{R C}_{i t}$. Let us further assume a budget constraint given by $I_{j t}=C_{j t}+P\left(\mathcal{R C}_{i t}, X_{i t}\right)$, where $I_{j t}$ is household income. To obtain the indirect utility function we then can replace $C_{j t}$ in equation (5) by $I_{j t}-P\left(\mathcal{R} \mathcal{C}_{i t}, X_{i t}\right)$.

Because $\mathcal{R} \mathcal{C}_{i t}$ is a dichotomous housing attribute, there is no first-order condition for utility maximization (see Bajari \& Kahn 2005). Recall that the implicit price to live near an RC is defined as $\gamma_{1 j}$. Utility maximization then implies:

$$
\begin{aligned}
& {[\mathcal{R C}=1] \Longrightarrow\left[\gamma_{1 j} \geq \alpha_{1 j} W_{i t}+\alpha_{2 j} Z_{j t}+\alpha_{3 j} X_{i t}\right]} \\
& {[\mathcal{R C}=0] \Longrightarrow\left[\gamma_{1 j} \leq \alpha_{1 j} W_{i t}+\alpha_{2 j} Z_{j t}+\alpha_{3 j} X_{i t}\right] .}
\end{aligned}
$$

Hence, if a household lives near an RC they are willing to pay at least $\gamma_{1 j}$, while if a household does not live near an RC they are willing to pay maximally $\gamma_{1 j}$.

Note that equation (6) is more general than Bajari \& Kahn (2005), who do not consider the interaction of consumption of other housing attributes with the willingness to pay for RCs. This does, however, introduce a source of endogeneity: equation (6) suffers from simultaneity bias because the consumption of housing attributes, $X_{i t}$, and whether a households lives nearby an $\mathrm{RC}$ are jointly determined. We investigate whether this bias is important, by using the approach outlined in Ekeland et al. (2004). They show that in additive non-parametric models, preferences and consumption can be identified. That is, Ekeland et al. (2004) propose to use $\mathrm{E}\left[X_{i t} \mid Z_{j t}\right]$ and 
$\mathrm{E}\left[X_{i t}^{2} \mid Z_{j t}\right]$ as instruments for $X_{i t}$. This is a valid approach because the hedonic price model is generically non-linear: the way in which the (latent) preferences for RCs relate to $X_{i t}$ is different from the way in which $X_{i t}$ relate to $Z_{j t}$. The latter provides us with the identifying variation to measure $\alpha_{3 j}$.

\subsection{Estimation of non-parametric hedonic price models}

The first step to identify latent preferences for RCs is to estimate the non-parametric hedonic price function as per equation (4). We follow a similar approach as Bishop \& Timmins (2018). We start with conditioning out the zip code and time fixed effects:

$$
\tilde{P}_{i j t}=\gamma_{1 j}\left(W_{i t}, X_{i t}, Z_{j t}\right) \tilde{\mathcal{R C}}_{i t}+\gamma_{2 j}\left(W_{i t}, X_{i t}, Z_{j t}\right) \tilde{X}_{i t}+\tilde{\epsilon}_{i t},
$$

where $\sim$ denotes that these are variables for which the fixed effects have been partialled out. This implies that everyone is assumed to have the same preferences regarding the house and time fixed effects (as is the case in Bajari \& Kahn 2005, for the unobserved housing attribute). We then use local linear regression techniques to estimate $\gamma_{1 j}$ :

$$
\left(\hat{\gamma}_{1 j}, \hat{\gamma}_{2 j}\right)=\underset{\gamma_{1 j}, \gamma_{2 j}}{\arg \min } \sum_{\ell=1}^{J} \prod_{k=1}^{\mathcal{K}} K\left(\frac{V_{i \ell t}^{k}-V_{i j t}^{k}}{h}\right) \times\left(\tilde{P}_{i \ell t}-\gamma_{1 j} \tilde{\mathcal{R C}}_{i t \mid \ell}-\gamma_{2 j} \tilde{X}_{i t \mid \ell}\right)^{2}
$$

where $\ell$ are (other) individuals, $\gamma_{1 j}$ are the parameters of interest, and $V_{i \ell t}=\left\{\frac{W_{i t \mid \ell}-\bar{W}}{\sigma_{W}}, \frac{X_{i t \mid \ell}-\bar{X}}{\sigma_{X}}, \frac{Z_{j t}-\bar{Z}}{\sigma_{Z}}\right\}$, where $k=1, \ldots, \mathcal{K}$ are the number of variables to be included in the kernel function. We specify $K(\cdot)$ to be a Gaussian kernel function:

$$
K\left(\frac{V_{i \ell t}^{k}-V_{i j t}^{k}}{h}\right)=\frac{1}{\sqrt{2 h \pi}} \mathrm{e}^{-\left(\frac{V_{i \ell t}^{k}-V_{i j t}^{k}}{2 h}\right)^{2}} .
$$

Hence, $K(\cdot)$ determines the vector of weights for an individual $j$. The weight is maximized when an individual $\ell$ with identical observable characteristics as $j$ lives in exactly the same house. The bandwidth $h$ determines how 'smooth' the function to be estimated is. When $h \rightarrow \infty$, equation (7) collapses to a standard linear hedonic price function. By contrast, if $h \rightarrow 0$ we estimate for each individual a separate (unweighted) regression, which would be impossible given that we typically would have only one observation per individual. 
The question remains what is the 'right' bandwidth. The previous applied literature usually just picks a somewhat arbitrary value of around 3 (see Bajari \& Kahn 2005, Bishop \& Timmins $2018,2019)$. Instead, we will use a 'leave-one-out' cross-validation procedure to determine $h$ :

$$
(\hat{h})=\underset{h}{\arg \min } \sum_{j=1}^{J}\left(\tilde{P}_{i j t}-\hat{\tilde{P}}_{i j t \neq j}(h)\right)^{2},
$$

where $\hat{\tilde{P}}_{i j t \neq j}$ is the predicted price for $j$ in a regression where $j$ is excluded. We exclude predicted prices below the $1^{\text {st }}$ percentile value and above the $99^{\text {th }}$ value to mitigate the issue that the outcome is affected by a few outlier values.

The second step of the estimation is to identify the preference parameters $\left\{\alpha_{1 j}, \alpha_{2 j}, \alpha_{3 j}\right\}$ using the estimates of $\gamma_{1 j}$ and data on $\left\{W_{i t}, X_{i t}, Z_{j t}\right\}$. Given equation (5), we estimate:

$$
\gamma_{1 j}^{*}=\alpha_{0} \alpha_{1} W_{i t}+\alpha_{2} Z_{j t}+\alpha_{3} X_{i t}+\mu_{j t}
$$

where $\gamma_{1 j}^{*}$ is the (latent) willingness to pay for an RC.

However, as shown in equation (6) we only identify lower bounds (when people do reside near an $\mathrm{RC}$ ) and upper bounds (when individuals do not reside near an $\mathrm{RC}$ ) because $\mathcal{R C}$ is a dummy variable. This implies:

$$
\begin{gathered}
\underline{\gamma}_{1 j}=\mathcal{R C}_{i t} \hat{\gamma}_{1 j}+\left(1-\mathcal{R} \mathcal{C}_{i t}\right) \min _{j}\left(\hat{\gamma}_{1 j}\right), \\
\bar{\gamma}_{1 j}=\mathcal{R} \mathcal{C}_{i t} \max _{j}\left(\hat{\gamma}_{1 j}\right)+\left(1-\mathcal{R} \mathcal{C}_{i t}\right) \hat{\gamma}_{1 j}
\end{gathered}
$$

Hence, we set the lower and upper bounds respectively to the minimum and maximum implicit price in the sample. ${ }^{12}$

Taking these boundaries into account, to recover the utility parameters in equation (11) we use

\footnotetext{
${ }^{12}$ Bajari \& Kahn (2005) assume that the second stage error term is normally distributed, so that they can use a Probit model where the coefficient related to the implicit prices is normalized to minus one. Given that $\mu_{j t} \sim N\left(0, \sigma^{2} J\right)$, the Probit model will lead to consistent estimates of $\left\{\alpha_{1 j}, \alpha_{2 j}, \alpha_{3 j}\right\}$, however, typically with rather large standard errors. By assuming explicitly defined upper and lower bounds our estimates are more precise and boil down to interval regressions.
} 
the following maximum likelihood function:

$$
\begin{array}{r}
\left(\hat{\alpha}_{0}, \hat{\alpha}_{1}, \hat{\alpha}_{2}, \hat{\alpha}_{3}\right)=\underset{\alpha_{0}, \alpha_{1}, \alpha_{2}, \alpha_{3}}{\arg \max } \sum_{j=1}^{J} \log \left(\Phi\left(\frac{\bar{\gamma}_{1 j}-\alpha_{0}-\alpha_{1} W_{i t}-\alpha_{2} Z_{j t}-\alpha_{3} X_{i t}}{\sigma}\right)-\right. \\
\left.\Phi\left(\frac{\underline{\gamma}_{1 j}-\alpha_{0}-\alpha_{1} W_{i t}-\alpha_{2} Z_{j t}-\alpha_{3} X_{i t}}{\sigma}\right)\right) .
\end{array}
$$

where $\Phi(\cdot)$ is the standard cumulative normal distribution and we assume $\mu_{j t} \sim N\left(0, \sigma^{2} J\right)$.

A remaining issue is that $X_{i t}$ may be endogenous. In other words, the amount of consumption of, for example, house size and the willingness to pay for RCs is jointly determined. As discussed earlier, we use $\mathrm{E}\left[X_{i t} \mid Z_{j t}\right]$ and $\mathrm{E}\left[X_{i t}^{2} \mid Z_{j t}\right]$ as instruments for $X_{i t}$. In the first stage, we regress continuous housing attributes on individual characteristics. In the second stage, we include control functions of the first stage residuals in equation (13) (Blundell \& Powell 2003, Yatchew 2003). ${ }^{13}$

\section{$5 \quad$ Regression results}

\subsection{Baseline estimates}

Table 4 reports the baseline results for the log-linear hedonic price function (see equation (1)). In column (1) we include all transactions. The opening of a refugee center has, on average, an effect on house prices of $e^{-0.0303}-1=-3.0 \%$. This effect is statistically significant at the $1 \%$ level. One may be worried that the placement of RCs is not random over space. That is, price developments in the rest of the Netherlands are different from those in areas near RCs, which is particularly so if there are unobserved differences between the $\mathrm{RC}$ locations and the rest of the Netherlands. In column (2), we therefore limit our sample to observations that are within $2 \mathrm{~km}$ of an $\mathrm{RC}$ that has been opened or will be opened, as well as observations that are within $2 \mathrm{~km}$ of a planned but canceled RC. Using this specification, the effect is $-5.1 \%$ (see column (2)).

There is some evidence that RCs that are canceled may be canceled because of local protests (see e.g. RTL Nieuws 2015). As a result, using a control group that includes canceled RCs might not be appropriate. In column (3) we estimate what we consider to be the preferred specification by only including observations that are within $2 \mathrm{~km}$ of an $\mathrm{RC}$ that has been opened (treatment

\footnotetext{
${ }^{13} \mathrm{An}$ important assumption of the control function approach is that the endogenous housing variables must be continuously distributed, which is fulfilled in our specific application.
} 
TABLE 4 - BASELINE RESUlts

(Dependent variable: the log of house price)

\begin{tabular}{|c|c|c|c|c|c|}
\hline & (1) & $(2)$ & $(3)$ & (4) & $(5)$ \\
\hline & Full sample & $\begin{array}{c}\text { Planned and } \\
\text { canceled }\end{array}$ & $\begin{array}{l}\text { Timing opening } \\
\text { of RCs only }\end{array}$ & $\begin{array}{l}\text { Event } \\
\text { study }\end{array}$ & $\begin{array}{c}\text { Distance } \\
\text { profile } \\
\end{array}$ \\
\hline Refugee center opened, $<2 \mathrm{~km}$ & $\begin{array}{c}-0.0303^{* * *} \\
(0.0077)\end{array}$ & $\begin{array}{c}-0.0524^{* * *} \\
(0.0086)\end{array}$ & $\begin{array}{c}-0.0599 * * * \\
(0.0089)\end{array}$ & See Fig. 6 & $\begin{array}{c}-0.0814^{* * *} \\
(0.0146)\end{array}$ \\
\hline Refugee center opened, $2-5 \mathrm{~km}$ & & & & & $\begin{array}{l}-0.0487 \\
(0.0350)\end{array}$ \\
\hline Refugee center opened, $5-10 \mathrm{~km}$ & & & & & $\begin{array}{c}0.0152 \\
(0.0147)\end{array}$ \\
\hline Housing characteristics & Yes & Yes & Yes & Yes & Yes \\
\hline Postcode fixed effects & Yes & Yes & Yes & Yes & Yes \\
\hline Year and month fixed effects & Yes & Yes & Yes & Yes & Yes \\
\hline Observations & $2,640,378$ & 318,193 & 194,436 & 194,436 & 194,436 \\
\hline$R^{2}$ & 0.92 & 0.93 & 0.93 & 0.93 & 0.93 \\
\hline
\end{tabular}

group) or will be opened (control group). Hence, the identifying assumption is that the timing of openings of RCs is random. The results are reported in column (3). The coefficient indicates that prices decrease by $-5.8 \%$ once an $\mathrm{RC}$ is opened. ${ }^{14}$

We examine whether the effect on house prices is transitory or permanent by undertaking an event study. We do not impose any structure on the temporal effects but allow for year-specific effects for our sample. The results of this specification are reported in Figure 6. The results show that at the moment of placement there is a very clear discrete negative jump in prices of $-3.9 \%$. After a few years, the effect seems to become more negative (up to $-8.9 \%, 10$ years after opening of an RC), but the coefficients are also less precisely estimated albeit still statistically significant at the $5 \%$ level. Jointly, the null hypothesis that the treatment effect is constant is rejected although the associated $F$-value of 6.94 is not particularly large. Overall, the results suggest that the effect of the opening of an $\mathrm{RC}$ on house prices is permanent. ${ }^{15}$

Next, we investigate whether the treatment effect extends beyond $2 \mathrm{~km}$. Because distance to the nearest RC varies over time, we can also identify those effects. The results in column (5) seem

\footnotetext{
${ }^{14}$ The effect of the opening of an RC on house prices using a threshold distance of $1 \mathrm{~km}$ is $-6.0 \%$, which is statistically significant at the $5 \%$ level. Using a $500 \mathrm{~m}$ threshold implies a point estimate of $-3.5 \%$. However, this effect is imprecisely estimated, which is not surprising given that there are only 11,000 observations left in this case. We will further discuss the role of distance (and direction of the effect) at the end of this section.

${ }^{15}$ The effect 5 years before opening is $-1.9 \%$ and just statistically significant. However, excluding the (small) sample of refugee centers that were opened and subsequently closed during the sample period this effect becomes negligible and statistically insignificant.
} 


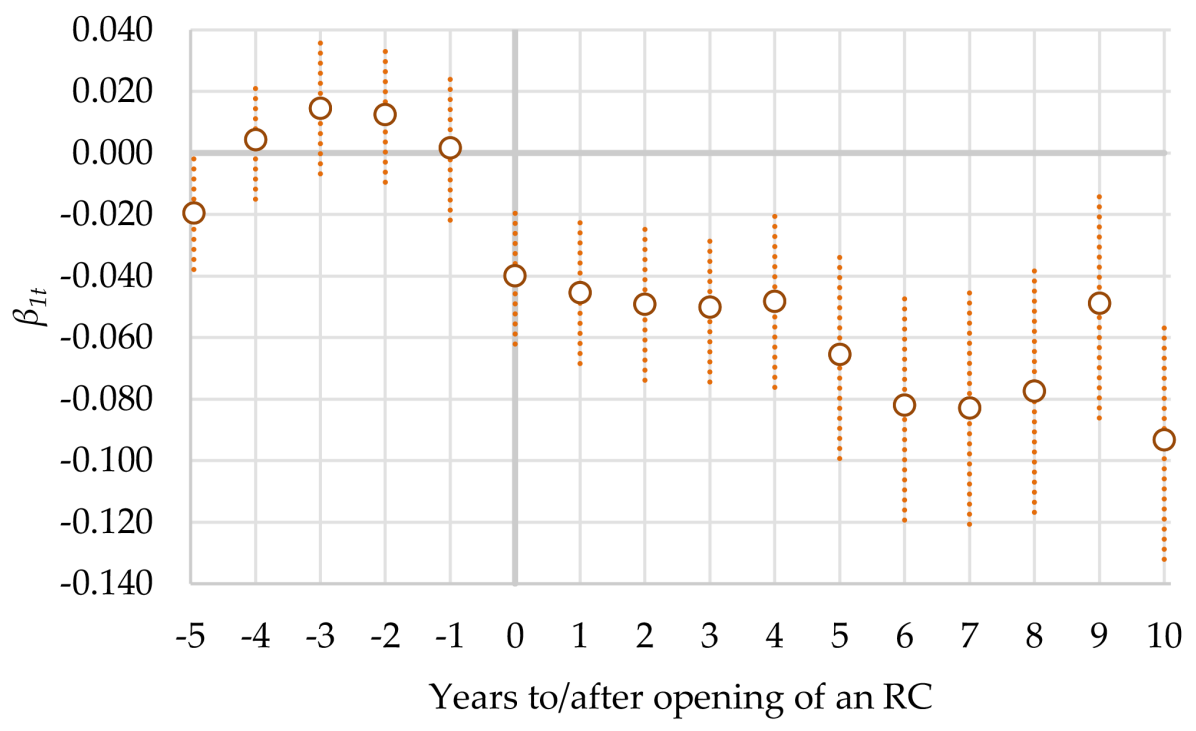

Figure 6 - Event STUdy

Notes: This figure re-estimates the specification reported in column (3), Table 4, but allows the effect of RCs to be dependent on the year to/after opening.

to confirm our baseline estimate and shows that the effect decays over distance. Within $2 \mathrm{~km}$ the effect is $-7.8 \%$ which is highly statistically significant. At $2-5 \mathrm{~km}$ the effect is still negative but it is imprecisely estimated. In any case, the point estimate suggest that it is considerably smaller than within $2 \mathrm{~km}$. Between $5-10 \mathrm{~km}$ we find a relatively small positive coefficient that is, however, not statistically significantly different from zero. ${ }^{16}$

\subsection{Extension: corridor analysis}

Here, we also consider to use an alternative approach to measure the impact of RCs on house prices. We construct $100 \mathrm{~m}$ wide corridors to the nearest shopping area based on the existing road network (see equation (2)). It seems more reasonable that the effect is located inside of those corridors and outside these corridors the effect might be due to RCs being opened in places that were declining in price for some other unobserved reason. We again estimate a specification including the whole of the Netherlands, with planned but canceled RCs as benchmark, and using the time variation in the opening dates of RCs only, just like in Table 4 . Table 5 reports the results.

Based on the full sample we find a negative effect on house prices inside the corridor and within

\footnotetext{
${ }^{16}$ Appendix C.1 contains a more granular distance profile. We find some evidence that the effect might be relevant up to $4 \mathrm{~km}$. That is, $2 \mathrm{~km}$ might be a conservative impact radius.
} 
TABle 5 - Regression RESUlts Using CORRIDORS TO THE NEAREST SHOPPING STREET (Dependent variable: the log of house price)

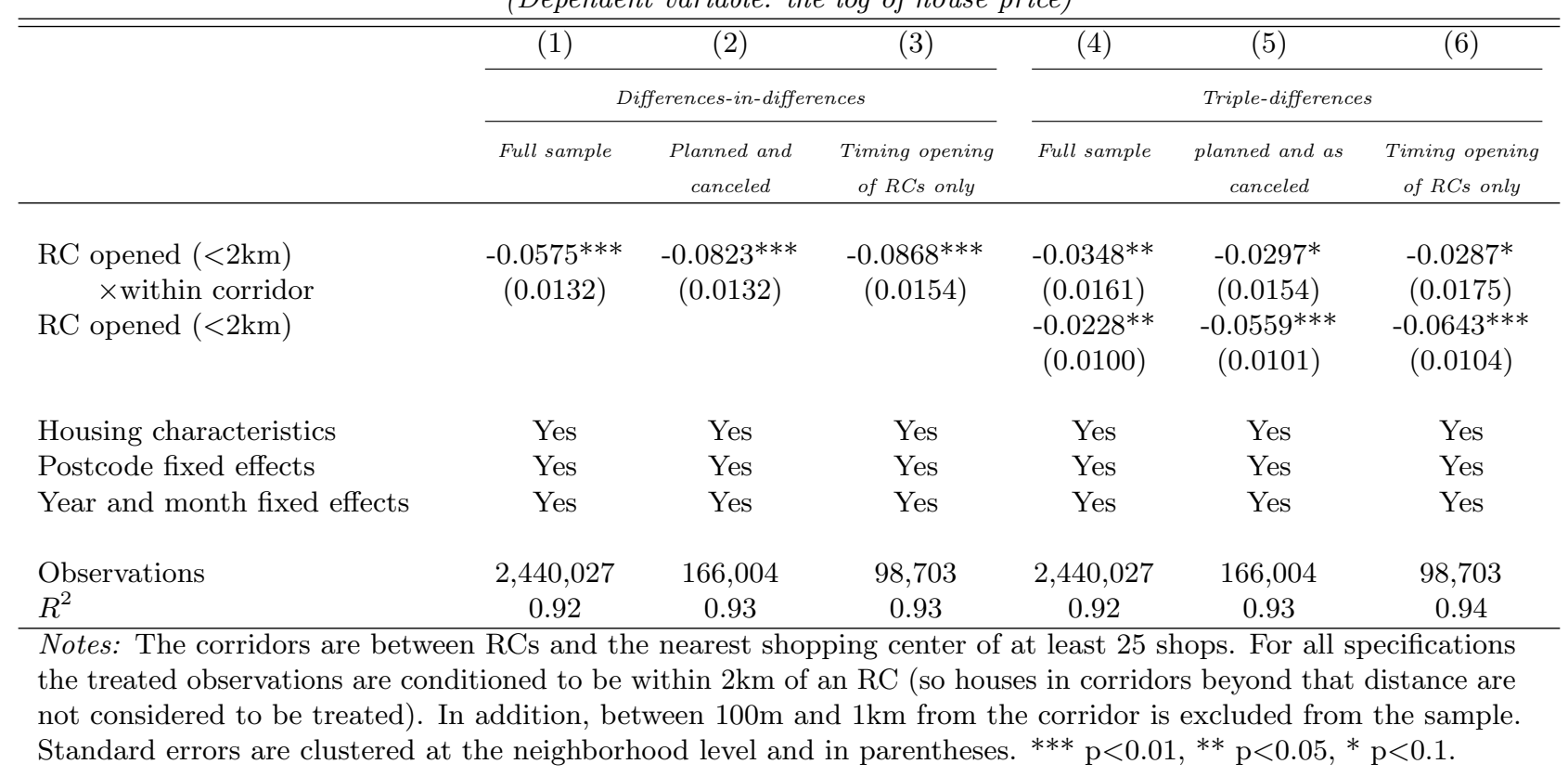

$2 \mathrm{~km}$ of an $\mathrm{RC}$ of $-5.6 \%$. The second specification is in line with the preferred baseline estimate, albeit somewhat stronger. We think this points towards the fact that effects within corridors may be stronger. We find a negative effect of $-7.9 \%$. Finally, using the variation in the timing of RCs only, the effect becomes $-8.3 \%$ which is again somewhat stronger than the preferred baseline estimate.

Next, we estimate a triple-differences specification where we compare the price change in the corridors to price changes outside the corridor but still within $2 \mathrm{~km}$ of a recently opened $\mathrm{RC}$ (see equation (3)). We report the results of this analysis in columns (4)-(6). If placement of RCs is correlated with declining prices due to unobserved reasons, assuming that this decline occurs in both the corridor and circle, we can consistently estimate the treatment effect by taking the difference between both. If there actually is an effect within $2 \mathrm{~km}$ of an $\mathrm{RC}$ we would underestimate the treatment effect. The results show that the effect is very much in line with what we found before. The effect inside the corridor within $2 \mathrm{~km}$ of an $\mathrm{RC}$ ranges from $-2.8 \%$ to $-3.4 \%$ and is statistically significant, albeit only at the $10 \%$ significance level. It seems very unlikely that just in the direction of shopping centers we pick up a spurious negative price trend. This strengthens our claim that the effect we find is causal. 


\subsection{Robustness and other extensions}

This subsection discusses several robustness checks and extensions, which are reported in Table 6. The specification in column (1) is based on the sub-sample of RCs that are still open at the end of the sample period. That is, RCs that have been closed are excluded. The effect $(-5.1 \%)$ is slightly smaller compared to the baseline estimate. Alternatively, we show in column (2) that, conditional on the RC being opened, the effect of closing an RC is $5.1 \%$. This is of the same order of magnitude as the opening of an RC. This provides additional support for the case that the estimates we provide measure a causal effect of RC openings/closings on house prices. It is highly unlikely that the timing of these events (opening and subsequent closing of an RC) exactly corresponds, for example, with some unobserved local policy intervention or unobserved economic shocks. ${ }^{17}$

Next, we re-estimate the baseline model using repeat sales. By including property fixed effects, we control for time-varying unobserved housing and location characteristics. The number of observations in the repeat sales model does, however, decrease considerably and the repeat sales model is potentially subject to selection bias. Nevertheless, the results reported in column (3), Table 6, suggest that although the effect is a bit smaller $(-5.1 \%)$, it is still statistically significant.

Alternatively, there may also be unobserved developments in the implicit prices of the control variables, which our preferred specification does not allow for. We therefore also estimate a time-varying coefficient model in which all implicit prices and the location fixed effects are allowed to vary over time. That is, we add interaction terms between the independent variables and 5-year period dummies. We report the results in column (4) and show that even with this very extensive model the opening of a refugee center still has a negative and statistically significant effect on house prices of $-2.9 \%$.

In column (5), Table 6, we use the difference between the log transaction price and log list price as dependent variable. The question is whether sellers take into account the price effect of the opening of a refugee center in setting the list price. Although sellers anticipate the majority of

\footnotetext{
${ }^{17}$ However, one may argue that closures of RCs may be non-random and related to locals' attitudes towards RCs. In other words, RCs may be particularly closed in areas where locals are opposing them. The results in column (1) show that supposedly endogenous closings do impact the results.
} 
the decrease in prices, buyers require an additional discount of 1.1 percentage points. This effect is statistically significant at the $1 \%$ level.

Opening of RCs may also impact the liquidity in the housing market (see for evidence on amenities and time on the market, Koster \& Van Ommeren 2019). We estimate the effect of the opening of a refugee center on the log of time on the market. The estimate in column (6) suggests that there is a $14 \%$ increase in the time on market, which is in line with the observation that list prices are set relatively high (higher than buyers accept apparently).

Column (7) reports the interaction effect with the total number of asylum applications in a specific year. In particular, we interacted the treatment effect with the (log) difference between the number of asylum request (see Figure 1) and the average of that number over time. The idea is that if there are many refugees coming to the Netherlands households might be more aware of their presence, which may influence their attitudes. Although there are large differences in the inflow of refugees, the findings reported in column (7) suggest that the number of refugees does not seem to affect the implicit prices of the opening of a refugee center.

More generally, to examine in more detail whether there has been a shift in attitudes regarding immigration, we examine whether the treatment effect systematically varies over time. We interacted the treatment dummy with 5-year period dummies. The results, stated in column (8), show that particularly at the end of the 1990s ( $-2.2 \%$, not significant) and the beginning of the 2000s $(-2.8 \%)$ the effect was less negative than the baseline estimate. This was a period when the Yugoslavian war on the European mainland, with the Netherlands directly involved in the peacekeeping force, resulted in a large inflow of refugees. Apparently, the opening of refugee centers was less of an issue at that time. ${ }^{18}$ After that, the effect seems to become more and more negative with the most recent period (2010-2015) showing effects of up to $-10.4 \%$. This seems to go hand-in-hand with the increased popularity of the more nationalist movements in the Netherlands (also at a European level) reflected in the rise of the nationalist political parties like LPF (founded in 2002) and PVV (founded in 2005). It may also relate to the increasing media coverage of the refugee crisis and (criminal) incidents where refugees were involved. ${ }^{19}$

\footnotetext{
${ }^{18}$ This is in line with the findings of Theebe (2002) who shows for several provinces in the Netherlands between 1997 and 1999 that refugee centers had no effect on house prices.

${ }^{19}$ An example is the widely covered Keulen incident. During New Year's Eve in 2015 a considerable amount of women were sexually harassed by foreigners, some of which turned out to be refugees (WDR 2016).
} 
TABle 6 - RoBUStNess AND EXTENSIONS

\begin{tabular}{|c|c|c|c|c|c|c|c|c|}
\hline & $\begin{array}{c}1) \\
\text { Opened RCs only }\end{array}$ & $\begin{array}{c}(2) \\
\text { Closings } \\
\end{array}$ & $\begin{array}{c}(3) \\
\text { Repeat sales }\end{array}$ & $\begin{array}{c}(4) \\
\text { Time-varying coef. }\end{array}$ & $\begin{array}{c}(5) \\
\text { Markup }\end{array}$ & $\begin{array}{c}(6) \\
\text { Time on market }\end{array}$ & $\begin{array}{c}(7) \\
\text { Number of refugees }\end{array}$ & $\begin{array}{c}(8) \\
\text { Over time }\end{array}$ \\
\hline Refugee center opened, $<2 \mathrm{~km}$ & $\begin{array}{c}-0.0520^{* * *} \\
(0.0142)\end{array}$ & & $\begin{array}{c}-0.0521^{* * *} \\
(0.0099)\end{array}$ & $\begin{array}{c}-0.0299^{* * *} \\
(0.0081)\end{array}$ & $\begin{array}{c}-0.0109^{* * *} \\
(0.0023)\end{array}$ & $\begin{array}{c}0.1507^{* * *} \\
(0.0513)\end{array}$ & $\begin{array}{c}-0.0596^{* * *} \\
(0.0090)\end{array}$ & \\
\hline Refugee center closed, $<2 \mathrm{~km}$ & & $\begin{array}{c}0.0494^{* * *} \\
(0.0155)\end{array}$ & & & & & & \\
\hline $\begin{array}{c}\mathrm{RC} \times(\log (\text { refugees })- \\
\log (\text { refugees }))\end{array}$ & & & & & & & $\begin{array}{c}0.0024 \\
(0.0096)\end{array}$ & \\
\hline $\mathrm{RC} \times D_{1990-1994}$ & & & & & & & & $\begin{array}{c}-0.0647 * * \\
(0.0265)\end{array}$ \\
\hline $\mathrm{RC} \times D_{1995-1999}$ & & & & & & & & $\begin{array}{l}-0.0218 \\
(0.0171)\end{array}$ \\
\hline $\mathrm{RC} \times D_{2000-2004}$ & & & & & & & & $\begin{array}{c}-0.0287^{* * *} \\
(0.0106)\end{array}$ \\
\hline $\mathrm{RC} \times D_{2005-2009}$ & & & & & & & & $\begin{array}{c}-0.0687^{* * *} \\
(0.0135)\end{array}$ \\
\hline $\mathrm{RC} \times D_{2010-2015}$ & & & & & & & & $\begin{array}{c}-0.1096^{* * *} \\
(0.0180)\end{array}$ \\
\hline Housing characteristics & Yes & Yes & No & Yes & Yes & Yes & Yes & Yes \\
\hline Postcode fixed effects & Yes & Yes & No & Yes & Yes & Yes & Yes & Yes \\
\hline Year and month fixed effects & Yes & Yes & Yes & Yes & Yes & Yes & Yes & Yes \\
\hline Observations & 147,839 & 105,439 & 40,012 & 194,436 & 194,436 & 191,774 & 194,436 & 194,436 \\
\hline$R^{2}$ & 0.93 & 0.94 & 0.76 & 0.96 & 0.25 & 0.26 & 0.93 & 0.93 \\
\hline
\end{tabular}

Notes: This table uses the variation in the timing of refugee centers only, see specification (3), Table 4. Standard errors are clustered at the neighborhood level and in parentheses. $* * * \mathrm{p}<0.01,{ }^{* *} \mathrm{p}<0.05,{ }^{*} \mathrm{p}<0.1$. 
Finally, house prices are a proxy for subjective well-being. To further support our findings we also examined the effects of RCs on satisfaction, perception of safety and employment using data on a Dutch housing survey. Unfortunately, this data is only available at the neighborhood level (we do not know the exact location of the survey respondents). The results of this analysis are discussed in Appendix E. We find that the opening of an RC increases the probability that households are dissatisfied with the neighborhood they live in; that those households are more likely to be willing to move within the next 2 years; and that they also experience more nuisance. The effects are economically sizable and support our main findings. Interestingly, households do not seem to feel more unsafe. We further find a decrease of unemployment, although the number of hours worked does not seem to be affected.

\subsection{Results of non-parametric hedonic price models}

In the previous analysis we do not identify the household demand function (WTP) but just differences in the marginal price for RCs. Instead, we aim to measure whether the WTP varies by RC attributes and household characteristics as to identify households' demand for RCs.

In Appendix D.2 we first report the results for a linear hedonic price model. For the restricted sample (2000-2015, for which we have data on household characteristics) we find an average WTP of $-€ 16,011$, which is $7.1 \%$ of the average house price. This is very close to the estimated treatment effect of our preferred specification listed in column (3), Table 4.

Next, we estimate the non-parametric price model (see equation (7)), of which the estimated WTP parameters are reported in Figure 7. In what follows we exclude the estimates below the $1^{\text {st }}$ and above the $99^{\text {nd }}$ percentile to ensure that our results are not driven by outliers. We find an average WTP for RCs of $-€ 18,259$, while the median WTP is $-€ 15,695$. The results show that there is substantial heterogeneity in preferences to live nearby an RC. Most values are negative, in line with expectations, but $6.2 \%$ of the estimates are positive.

In Table 7 we report the second-stage results. Recall that we do not point-identify the WTP of households because our variable of interest is dichotomous. Hence, we estimate equation (13) to be able to recover the utility parameters $\left\{\alpha_{1 j}, \alpha_{2 j}, \alpha_{3 j}\right\}$. In column (1) we explain the variation in WTP-parameters only by attributes of refugee centers. In line with expectations, we find that the effects are stronger for larger RCs. When the capacity of the nearest RC increases by 


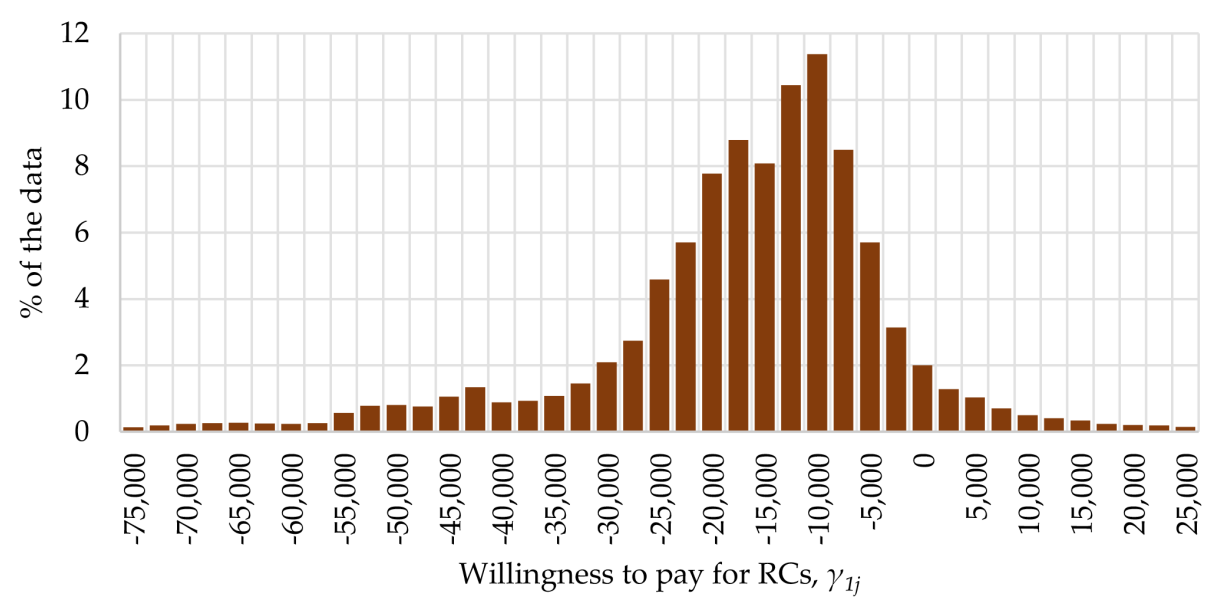

Figure 7 - Willingness to PAY FOR REFUgeE CENTERS

Notes: We report here the willingness to pay for refugee centers based on the estimates of equation (7).

100 , the WTP decreases by $€ 3,330$, which is almost $20 \%$ of the average WTP. More specifically, for a small WTP of 50 refugees, the estimated WTP would be $-€ 1,665$, while for a large RC of 1,000 refugees, the WTP would be $-€ 33,300$. We do not find a statistically significant effect for whether an RC is located within a new building in comparison to an existing one. Hence, the opening of an RC does not seem to be correlated to effects of new construction of buildings. ${ }^{20}$

In column (2) we add household characteristics. We find weak evidence that households with a higher disposable income have a more negative WTP. For example, a standard deviation increase in income (about $€ 23,642$ ) implies a decrease in the WTP of $€ 872$. We also find that foreign-born people do care less about the opening of an RC. Their willingness to pay is $€ 7,854$ more positive (41\% of the average WTP). This makes sense: foreign-born people are more likely to be of a similar ethnicity or might have a refugee background themselves, which makes it likely that they are more favorable towards the opening of an RC nearby.

Column (3) adds housing attributes as additional controls. We find that the previous results related to RC capacity, income, and being foreign-born are robust. However, we also do find negative effects for young individuals and couples. These effects are, however, not robust if we address endogeneity of housing attributes in column (4). More specifically, we regress the number of rooms, house size, house size squared, and the cubic of house size, on polynomials of

\footnotetext{
${ }^{20}$ We also considered to use relative capacity, which is capacity of the RC relative to the local population. In Appendix D.1 we show that relative capacity is not associated with a different WTP, while absolute capacity has a strong impact on the WTP. Moreover, endogeneity concerns with relative capacity are likely more pronounced.
} 
TABle 7 - EXPlaining HeTEROGENEITY IN THE WTP FOR RCs (Dependent variable: the willingness to pay for refugee centers, $\hat{\gamma}_{1 j}^{*}$ )

\begin{tabular}{|c|c|c|c|c|}
\hline & (1) & $(2)$ & (3) & (4) \\
\hline & & $\begin{array}{l}\text { Maximum } \\
\text { likelihood }\end{array}$ & & $\begin{array}{c}\text { Maximum likelihood }+ \\
\text { control function }\end{array}$ \\
\hline $\mathrm{RC}$ is newly built & $\begin{array}{c}6,434 \\
(4,606)\end{array}$ & $\begin{array}{c}5,777 \\
(4,550)\end{array}$ & $\begin{array}{c}1,862 \\
(3,553)\end{array}$ & $\begin{array}{c}2,911 \\
(3,692)\end{array}$ \\
\hline $\mathrm{RC}$ capacity (in 100s) & $\begin{array}{c}-3,330^{* * *} \\
(919)\end{array}$ & $\begin{array}{c}-3,313^{* * *} \\
(917)\end{array}$ & $\begin{array}{c}-3,065^{* * *} \\
(902)\end{array}$ & $\begin{array}{c}-2,924^{* * * *} \\
(904)\end{array}$ \\
\hline Income (in $s d$ ) & & $\begin{array}{c}-872^{*} \\
(452)\end{array}$ & $\begin{array}{l}-537 \\
(388)\end{array}$ & $\begin{array}{c}-1045^{* * *} \\
(351)\end{array}$ \\
\hline Age $30-49$ & & $\begin{array}{l}168 \\
(729)\end{array}$ & $\begin{array}{c}-1,309^{* * *} \\
(478)\end{array}$ & $\begin{array}{l}-523 \\
(507)\end{array}$ \\
\hline Age $50-69$ & & $\begin{array}{l}2,399^{*} \\
(1,487)\end{array}$ & $\begin{array}{l}-250 \\
(871)\end{array}$ & $\begin{array}{c}2,424^{* *} \\
(1,137)\end{array}$ \\
\hline Age $\geq 70$ & & $\begin{array}{c}4,705 \\
(3,121)\end{array}$ & $\begin{array}{c}2,849 \\
(2,656)\end{array}$ & $\begin{array}{c}10,297^{* * * *} \\
(3,135)\end{array}$ \\
\hline Foreign-born & & $\begin{array}{c}7,854^{* * *} \\
(2,044)\end{array}$ & $\begin{array}{c}6,623^{* * *} \\
(1,729)\end{array}$ & $\begin{array}{c}7,022^{* * *} \\
(1,793)\end{array}$ \\
\hline Household size & & $\begin{array}{c}616 \\
(498)\end{array}$ & $\begin{array}{c}44 \\
(364)\end{array}$ & $\begin{array}{c}-1,655^{* *} \\
(719)\end{array}$ \\
\hline Household - couple & & $\begin{array}{l}2,380^{*} \\
(1,421)\end{array}$ & $\begin{array}{c}-1,660^{*} \\
(990)\end{array}$ & $\begin{array}{c}109 \\
(1,116)\end{array}$ \\
\hline Household - kids & & $\begin{array}{c}3,364^{* * *} \\
(981)\end{array}$ & $\begin{array}{l}1,005 \\
(963)\end{array}$ & $\begin{array}{c}226 \\
(1,023)\end{array}$ \\
\hline Household - share male & & $\begin{array}{c}330 \\
(538)\end{array}$ & $\begin{array}{l}-250 \\
(438)\end{array}$ & $\begin{array}{l}-389 \\
(477)\end{array}$ \\
\hline Housing attributes & No & No & Yes & Yes \\
\hline Number of observations & 57,728 & 57,728 & 57,728 & 57,728 \\
\hline McFadden Pseudo- $R^{2}$ & 0.011 & 0.012 & 0.023 & 0.023 \\
\hline
\end{tabular}

household characteristics. We then use the first-stage errors as control functions in the second stage. The coefficients do change somewhat - we now find a strong positive effect for elderly people and a negative effect based on household size - but the main effects we find earlier with respect to RC capacity, income, and foreign-born are remarkably unaltered. Taking this as our final preferred estimate, we find that the capacity effect is about $-€ 3.0$ thousand, the income effect $-€ 1000$, and the non-western foreigner effect $-€ 7.0$ thousand.

Overall, our results suggest that heterogeneity is of key importance when analyzing the WTP for RCs. We find consistent evidence that support of the local population will be greater if RCs are smaller and when the population is ethnically more diverse (i.e. if places have a higher share of foreign-born people). 


\subsection{Where to build RCs?}

Given the WTP estimates (see Table 7, column (4)) and the average demographics in an area we can determine what is the best location to open new RCs, given local attitudes towards refugees. Let us consider an inflow of 12,500 additional refugees (which is about the standard deviation of asylum applications throughout the years). We consider two cases: one where only small RCs are opened with a maximum capacity of 100 refugees. In the second case only large RCs are opened with a capacity of 2000 refugees. We assume that RCs will be opened in the centroid of neighborhoods. We draw circles of $2 \mathrm{~km}$ around each centroid to determine average household characteristics for that particular neighborhood. We evaluate the WTP estimates at the average housing characteristics in the sample and choose those neighborhoods with the highest total WTP which is based on the average WTP and total number of housing units in that particular area. Furthermore, we allow for the construction of only one RC per municipality, which is the current $_{\text {practice. }}{ }^{21}$

At least three caveats are important to mention before considering the results. First, we do not take into account preferences of refugees themselves, which would be necessary if one is willing to undertake a full cost-benefit analyses of the placement of RCs. Second, we do not take into account other costs, such as construction costs and wages for the staff, which may vary between locations and may be higher when RCs are small. Third, once RCs are opened preference-based sorting may occur, which then leads to a different demographic composition of the neighborhood. We do not take into account the price effects of RC-induced sorting, which are typically considered second order effects.

We report maps of the (average) households' WTP for RCs in Figure 8. In Figure 8a we focus on the construction of small RCs. One can observe that the WTP vastly differs between areas. For example, it is generally slightly positive in ethnically more diverse areas such as Amsterdam, Rotterdam and The Hague. This is despite the higher income levels in these areas. Especially in rural areas the average estimated WTP is negative and can be up to $-€ 6,437$. Because those RCs are considerably smaller than the average, this is much lower than the average WTP estimated earlier. We also show the most optimal set of targeted locations, given the restriction

\footnotetext{
${ }^{21}$ Otherwise, because of household sorting, the resulting outcome would be that RCs are concentrated in only a few places. Note that for simplicity all neighborhoods are considered as potential location even if they already have an RC based on the current situation.
} 


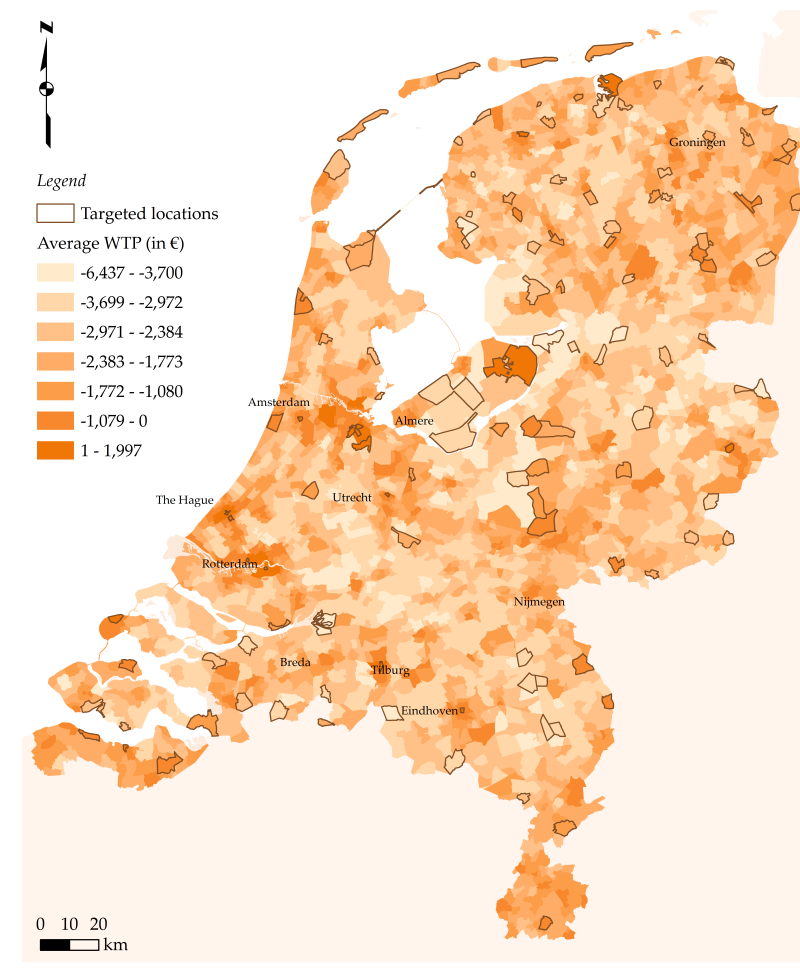

(A) RC CAPACITY OF 100

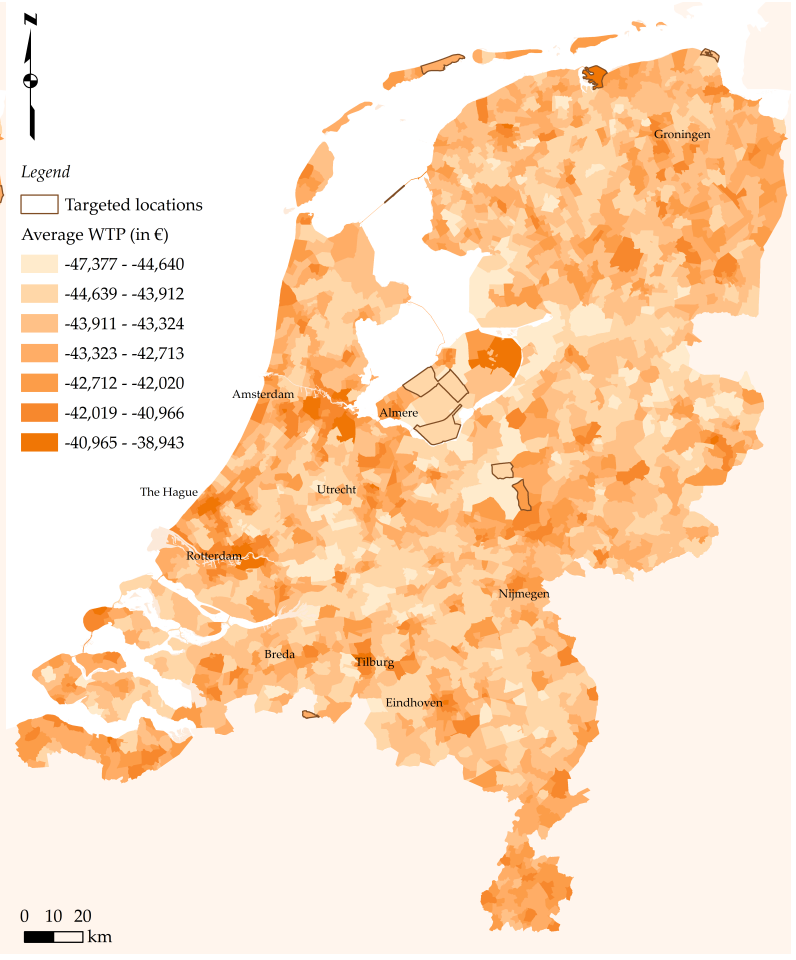

(B) RC CAPACITY OF 1500

Notes: We report the average willingness to pay per neighborhood. We rank the areas with the highest total WTP and assign one RC per municipality to determine the set of selected locations. We consider a sudden inflow of 12,500 refugees.

\section{Figure 8 - THE WTP FOR RCS}

that only one RC per municipality is allowed. Given the capacity and assumed inflow of refugees, this means that 125 new RCs have to be opened. The figure shows that at least the areas with a positive WTP are selected. However, because there are too few areas with a positive WTP also areas with a (strong) negative average WTP are selected that have a low population density. Hence, with low densities fewer households experience the supposed discontent of an RC. All in all, the average WTP of the selected locations is positive and $€ 1.8$ million per $\mathrm{RC}^{22}$

We also consider the alternative scenario where 9 new RCs will be opened with a capacity of 1500. Because we have assumed a relationship between household characteristics and the WTP for RCs, we find a perfect correlation between predicted WTP in both scenarios. However, the average WTP is now strongly negative in all cases (on average $-€ 43,145$ ). Furthermore, the targeted locations are somewhat different: instead of building RCs in dense areas, the results now suggests to open RCs in mostly rural areas. The average willingness to pay is now negative

\footnotetext{
${ }^{22}$ One may be surprised that we find an overall positive effect of RCs, despite the observation that only $6.2 \%$ of the WTP estimates are positive (see Figure 7). However, note that the areas with positive WTP are areas with a high population density, so that the overall estimate is positive.
} 
and $-€ 1.1$ million per RC.

The results of this back-of-the envelope calculation should be interpreted with caution. Nevertheless, we find a clear trade-off in terms of the size and location of RCs, i.e. our estimates suggest that the support for RCs can be improved by opening relatively small RCs in more ethnically diverse areas. These areas are typically located in some of the major urban agglomerations (cities) in the Netherlands. If RCs, however, are associated with a negative WTP, opening RCs in dense areas should, to the extent possible, be avoided.

\section{Conclusion}

The number of refugees around the world has increased steadily in the last decade to 25.9 million refugees in 2018 (UNHCR 2019). This has had a profound impact on many countries, regions and cities. Many of these refugees have to await their asylum procedure in dedicated refugee centers. In this paper we use data on refugee centers opened in the Netherlands between 1987 and 2015 to measure attitudes of locals towards immigration. More specifically, using detailed house price data we examine how much households are willing to pay to avoid living near refugee centers (RCs).

The results show that house prices within $2 \mathrm{~km}$ of a refugee center decline by about $3-6 \%$ after opening of a refugee center. Closing down an $\mathrm{RC}$ has a similar but positive effect. The effect on house prices is persistent over time and is present even 10 years after opening. The effect seems to be particularly negative towards the end of the sample period, corresponding to an increased popularity of nationalist parties. Our results are robust to using a triple-differences strategy where we compare price changes in corridors to local shopping areas to price changes outside those corridors but within close distance $(2 \mathrm{~km})$ of an RC.

We further estimate non-parametric hedonic price regressions to identify individual preferences regarding the opening of refugee centers. The median WTP is about $-€ 16$ thousand but we show that there is considerable heterogeneity in the WTP. For example, the WTP becomes $€ 3.0$ thousand lower for a 100 person increase in the capacity of a refugee center. A standard deviation increase in income results in a $€ 1$ thousand lower WTP. Moreover, foreign-born people, ceteris paribus, have a higher WTP of about $€ 7$ thousand so they seem to be more tolerant regarding the opening of RCs near their properties. The results suggest that households' attitudes towards 
immigration, although sometimes positive, are mostly negative in the Netherlands. ${ }^{23}$

Of course, the decision to open refugee centers relates to other factors than just households' preferences, such as general humanitarian concerns as well as possibilities for future integration. Although such considerations are important, we add to this notion that the local attitudes towards refugee centers may be less negative or even positive when RCs are kept relatively small and are placed in ethnically diverse areas. This is opposite to the current practice where RCs are typically large and also built in areas with a low degree of ethnic diversity, which are typically more rural areas.

\footnotetext{
${ }^{23}$ We back this up by direct evidence on subjective well-being: we find that households have an increased intention to move, have a higher probability of experiencing neighborhood dissatisfaction, and experience more nuisance when RCs are opened. For these results, we again refer to Appendix E.
} 


\section{References}

Achbari, W. \& Leerkes, A. (2017), 'Van perceptie naar feit', Cahier (2017-16).

Akgündüz, Y., Van den Berg, M. \& Hassink, W. (2018), 'The Impact of the Syrian Refugee Crisis on Firm Entry and Performance in Turkey.', The World Bank Economic Review 32(1), 19-40.

Algemeen Dagblad (2016), 'Protest tegen azc eindigt met ingreep door politie en ME'.

Åslund, O. (2005), 'Now and Forever? Initial and Subsequent Location Choices of Immigrants', Regional Science and Urban Economics 35(2), 141-165.

Bajari, P. \& Benkard, C. (2005), 'Demand Estimation with Heterogeneous Consumers and Unobserved Product Characteristics: A Hedonic Approach', Journal of Political Economy $\mathbf{1 1 3}(6), 1239-1276$.

Bajari, P. \& Kahn, M. (2005), 'Estimating Housing Demand With an Application to Explaining Racial Segregation in Cities', Journal of Business and Economic Statistics 23(1), 20-33.

Bakker, K. (2016), 'Steenbergen: Het Protest dat de toon zette voor AZC-debat'.

Bishop, K. \& Timmins, C. (2018), 'Using Panel Data to Easily Estimate Hedonic Demand Functions', Journal of the Association of Environmental and Resource Economists 5(3), 517543.

Bishop, K. \& Timmins, C. (2019), 'Estimating the Marginal Willingness to Pay Function Without Instrumental Variables', Journal of Urban Economics 109, 66-83.

Blundell, R. \& Powell, J. (2003), Endogeneity in Nonparametric and Semiparametric Regression Models, in M. Dewatripont, L. Hansen \& S. Turnovsky, eds, 'Advances in Economics and Econometrics: Theory and Applications', Cambridge University Press, Cambridge.

Borjas, G. (2003), 'The Labor Demand Curve is Downward Sloping: Reexamining the Impact of Immigration on the Labor Market', Quarterly Journal of Economics 118(4), 1335-1374.

Brown, J. \& Rosen, H. (1982), 'On the Estimation of Structural Hedonic Price Models', Econometrica 50(3), 765-768. 
CBS (2018), Uit de startblokken - Cohortstudie naar recente asielmigratie, Technical report, CBS, Den Haag.

Daams, M. N., Proietti, P. \& Veneri, P. (2019), The Effect of Asylum Seeker Reception Centers on Nearby House Prices: Evidence from the Netherlands, in G. Tintorini, A. Alessandrini \& F. Natale, eds, 'Diversity, residential segregation, concentration of migrants: a comparison across EU cities. Findings from the Data Challenge on Integration of Migrants in Cities (D4I)', Publications Office of the European Union, Luxembourg.

De Stentor (2017), 'Protest tegen azc in Apeldoorn'.

DeStem, B. (2017), 'AZC-protest in Gemeente Bernheze zonder Incidenten'.

Docquier, F., Ozden, C. \& Peri, G. (2014), 'The Labour Market Effects of Immigration and Emigration in OECD Countries', Economic Journal 124(579), 1106-1145.

Duranton, G. \& Overman, H. (2005), 'Testing for Localization Using Micro-Geographic Data', Review of Economic Studies 72(4), 1077-1106.

Duranton, G. \& Overman, H. (2008), 'Exploring the Detailed Location Patterns of U.K. Manufacturing Industries Using Microgeographic Data', Journal of Regional Science 48(1), 213-243.

Dustmann, C., Fabbri, F. \& Preston, I. (2005), 'The Impact of Immigration on the British Labour Market', Economic Journal 115(507), F324-F341.

Dustmann, C. \& Preston, I. (2007), 'Racial and Economic Factors in Attitudes to Immigration', The B.E. Journal of Economic Analysis 8 Policy 7(1), 1-39.

Edin, P.-A., Fredriksson, P. \& Åslund, O. (2003), 'Ethnic Enclaves and the Economic Success of Immigrants - Evidence from a Natural Experiment', Quarterly Journal of Economics 118(1), 329-357.

Ekeland, I., Heckman, J. \& Nesheim, L. (2002), 'Identifying Hedonic Models', American Economic Review 92(2), 304-309.

Ekeland, I., Heckman, J. \& Nesheim, L. (2004), 'Identification and Estimation of Hedonic Models', Journal of Political Economy 112(S1), S60-S109. 
European Commission (2015), 'A European Agenda on Migration', COM(2015) 240 final .

Forrest, J., Hermes, K., Johnston, R. \& Poulsen, M. (2013), 'The Housing Resettlement Experience of Refugee Immigrants to Australia', Journal of Refugee Studies 26(2), 187-206.

Ivarsflaten, E. (2008), 'What Unites Right-Wing Populists in Western Europe? Re-Examining Grievance Mobilization Models in Seven Successful Cases', Comparative Political Studies 41(1), 3-23.

Klier, T. \& McMillen, D. (2008), 'Evolving Agglomeration in the U.S. Auto Supplier Industry', Journal of Regional Science 48(1), 245-267.

Koster, H. R. A., Pasidis, I. \& Van Ommeren, J. (2017), 'Shopping Externalities and Retail Concentration: Evidence from the Netherlands', Journal of Urban Economics (Forthcoming).

Koster, H. R. A. \& Van Ommeren, J. (2019), 'Place-based Policies and the Housing Market', Review of Economics and Statistics 101(3), 1-15.

Kuppens, J., Scholten, L. \& Ferwerda, H. (2017), Risicoanalyse en monitoring leefbaarheid en veiligheid rondom AZC Apeldoorn, Technical report, Bureau Beke.

Lastrapes, W. D. \& Lebesmuehlbacher, T. (2018), 'The European Refugee Crisis and House Prices: Evidence from the United Kingdom', Working paper, University of Georgia .

NRC (2018), 'Op papier hebben we al de snelste asielprocedure'.

Obdeijn, H. \& Schrover, M. (2009), Komen en Gaan - Immigratie en emigratie in Nederland vanaf 1550, Uitgeverij Bert Bakker, Amsterdam.

Rosen, S. (1974), 'Hedonic Prices and Implicit Markets: Product Differentiation in Pure Competition', Journal of Political Economy 82(1), 34.

RTL Nieuws (2015), 'Protest Tegen Azc Leidt Vaak Tot Minder Vluchtelingen'.

Silverman, B. (1986), Density Estimation for Statistics and Data Analysis, Chapman and Hall, New York.

Theebe, M. (2002), 'Asielzoekers en de waarde van uw woning', ESB, 87e jaargang, nr. 4342, pagina 24, 11 january 2002 . 
Toonen, A. (2015), 'Protest Tegen AZC Enschede 'Duur Feestje van de Democratie".

Tumen, S. (2016), 'The Economic Impact of Syrian Refugees on Host Countries: Quasiexperimental Evidence from Turkey', American Economic Review: Papers and Proceedings 106(5), 456-460.

UNHCR (2019), UNHCR Global Trends 2018, Technical report, available at www.unhcr.org.

Volkskrant (2016), 'Drie Arrestanten Azc-protest Heesch Komen uit Andere Gemeente'.

WDR (2016), "fakten zur kölner silvesternacht: Wer sind die täter?".

URL: $w w w . w d r . d e$

Yatchew, A. (2003), Semiparametric Regression for the Applied Econometrician, Cambridge University Press, Cambridge. 


\section{Online Appendix A}

\section{A.1 Descriptives per refugee center category}

Table A1 shows the descriptives for house price dataset, which we split between observations near RCs that were realized before 2015, those that were planned to be opened after 2015 (and had a reported opening date), those that were opened and closed before 2015, and those that were planned after 2015 but were canceled.

House prices are highest in locations were refugee centers will be or are closed $(€ 226,333)$ and lowest were they are planned $(€ 181,549)$. The realized refugee centers, however, show an average transaction price (€203,030), which is very close to that in the full sample. Housing characteristics across the different categories also differ a bit. This highlights that it is important to control for housing characteristics in the regression analyses.

Unsurprisingly, given the size of the dataset, all of the differences in the means across the refugee center categories are statistically significant. In any case, our identification strategy will address any potential non-random placement. 
TABle A1 - Descriptive STATISTICs: HOUSE PRICE DATA PER REFUGEe CENTER CATEGORY

\begin{tabular}{|c|c|c|c|c|c|c|c|c|}
\hline & \multicolumn{2}{|c|}{ Realized } & \multicolumn{2}{|c|}{ Planned } & \multicolumn{2}{|c|}{ Closed } & \multicolumn{2}{|c|}{ Canceled } \\
\hline & $(1)$ & $(2)$ & $(3)$ & (4) & $(5)$ & (6) & $(7)$ & $(8)$ \\
\hline & mean & sd & mean & sd & mean & sd & mean & sd \\
\hline Transaction price & 203,030 & 110,218 & 181,549 & 100,808 & 226,333 & 129,554 & 207,923 & 120,347 \\
\hline Size in $\mathrm{m}^{2}$ & 120.8 & 36.37 & 115.0 & 37.39 & 109.5 & 41.98 & 114.4 & 37.76 \\
\hline Number of rooms & 4.446 & 1.310 & 4.254 & 1.299 & 3.964 & 1.470 & 4.296 & 1.321 \\
\hline Terraced property & 0.347 & 0.476 & 0.293 & 0.455 & 0.216 & 0.411 & 0.314 & 0.464 \\
\hline Semi-detached property & 0.317 & 0.465 & 0.255 & 0.436 & 0.199 & 0.399 & 0.249 & 0.432 \\
\hline Detached property & 0.137 & 0.343 & 0.124 & 0.330 & 0.110 & 0.313 & 0.102 & 0.303 \\
\hline Property has garage & 0.372 & 0.483 & 0.303 & 0.460 & 0.293 & 0.455 & 0.278 & 0.448 \\
\hline Property has garden & 0.971 & 0.169 & 0.975 & 0.155 & 0.976 & 0.153 & 0.975 & 0.155 \\
\hline Maintenance state is good & 0.868 & 0.338 & 0.864 & 0.343 & 0.876 & 0.330 & 0.858 & 0.349 \\
\hline Property has central heating & 0.903 & 0.295 & 0.883 & 0.321 & 0.878 & 0.328 & 0.889 & 0.314 \\
\hline Property is (part of) listed building & 0.00498 & 0.0704 & 0.00484 & 0.0694 & 0.0176 & 0.131 & 0.00569 & 0.0752 \\
\hline construction year 1945-1959 & 0.0718 & 0.258 & 0.0803 & 0.272 & 0.0454 & 0.208 & 0.0747 & 0.263 \\
\hline construction year 1960-1970 & 0.152 & 0.359 & 0.159 & 0.366 & 0.135 & 0.342 & 0.155 & 0.362 \\
\hline construction year 1971-1980 & 0.188 & 0.391 & 0.166 & 0.372 & 0.129 & 0.335 & 0.157 & 0.363 \\
\hline construction year 1981-1990 & 0.156 & 0.363 & 0.137 & 0.344 & 0.128 & 0.334 & 0.138 & 0.345 \\
\hline construction year 1991-2000 & 0.145 & 0.352 & 0.128 & 0.334 & 0.117 & 0.321 & 0.121 & 0.326 \\
\hline construction year $>2000$ & 0.0908 & 0.287 & 0.0763 & 0.265 & 0.0805 & 0.272 & 0.0833 & 0.276 \\
\hline
\end{tabular}




\section{Online Appendix B}

\section{B.1 Concentration of refugee centers}

In this Appendix section we test whether refugee centers are spatially concentrated. If RCs are randomly distributed over space, it is less likely that there will be a strong correlation between unobservable locational endowments and RCs.

Hence, we employ a point-pattern methodology to test for the concentration of RCs, which exploits the fact that our data is continuous over space. ${ }^{24}$ More specifically, we employ the method introduced by Duranton \& Overman $(2005,2008)$. Their concentration index controls for overall agglomeration, is invariant to scale and aggregation and, importantly, provides an indication of statistical significance. Below, we briefly discuss the procedure. For more details, we refer to Duranton \& Overman $(2005,2008)$.

Let $K(d)$ denote the estimated kernel density at a given distance $d, d_{i k}$ denotes the distance between location $i$ and $k$, where $i=1, \ldots, n$. Then:

$$
K(d)=\frac{1}{n(n-1) h} \sum_{i=1}^{n-1} \sum_{k=i+1}^{n} \Omega\left(\frac{d-d_{i k}}{h}\right)
$$

where $n$ is the total number of realized and canceled RCs in 2015. $h$ is the bandwidth and:

$$
\Omega(\cdot)=\frac{1}{\sqrt{2 \pi}} \mathrm{e}^{-\frac{1}{2}\left(\frac{d-d_{i k}}{h}\right)^{2}} .
$$

Equation (B.2) implies that we use a normal density function. Following Duranton \& Overman (2005, 2008) and Klier \& McMillen (2008), we use a bandwidth $h$ equal to Silverman's plug-in bandwidth (see Silverman 1986). More specifically, $h=1.06 \sigma_{d_{i k}} n^{-1 / 5}$, where $\sigma_{d_{i k}}$ is the standard deviation of the estimated bilateral distances between RCs. Distances $d$ cannot be negative, so we use the reflection method, proposed by Silverman (1986), to deal with this issue.

We aim to test whether the estimated concentration is statistically different from a random geographical pattern, so we have to define counterfactual location patterns. For each of the 1000 bootstrap runs, we draw $n$ locations and put them randomly across the Netherlands. ${ }^{25}$

\footnotetext{
${ }^{24}$ It has been argued that many measures of concentration use arbitrary spatial units (such as counties, cities or zip codes), which may be problematic as they may lead to biases in the measure of concentration.

${ }^{25}$ There are almost an infinite ways to construct counterfactuals (such as using zip code locations or correct for
} 


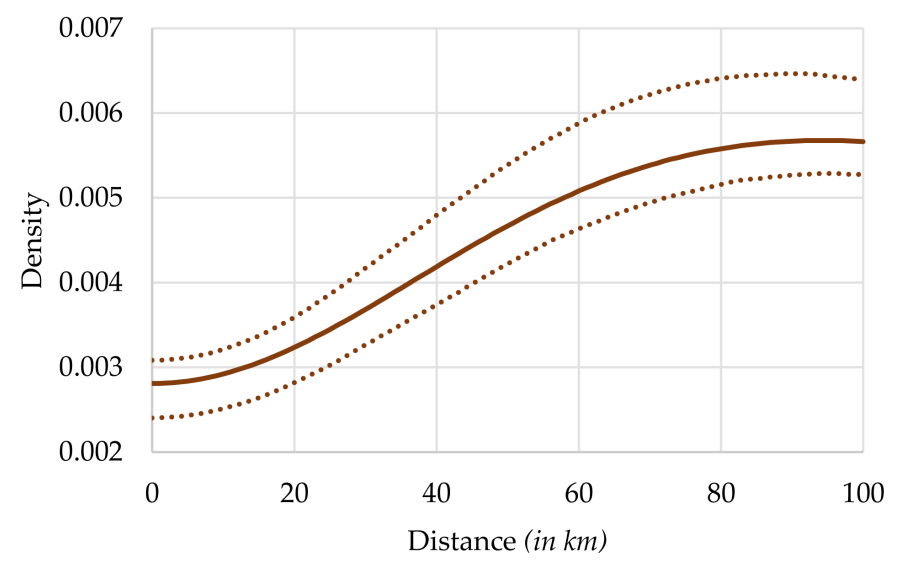

FiguRE B1 - $K$-DENSITY FOR ALL RCS

Notes: The dotted lines represent respectively the lower and upper $5 \%$ global confidence band.

To investigate whether there is statistically significant concentration of RCs we calculate the difference between $\hat{K}(d)$ and the upper confidence band of the randomly generated bomb patterns, denoted by $\bar{K}(d)$. RCs may also be significantly dispersed, then $\hat{K}(d)<\underline{K}(d)$. To define $\underline{K}(d)$ and $\bar{K}(d)$, we treat each of the estimated density functions for each simulation as a single observation. Following Duranton \& Overman (2005), we choose identical local confidence levels in such a way that the global confidence level is $5 \%$.

We report the results when we estimate global concentration indices as per equation (B.1) for each distance below the median bilateral distances between RC location. In Figure B1 we report the results when including all RCs. We can clearly see that the actual distribution of RCs in the Netherlands falls well within the confidence bands at each distance $d$.

One may argue that the canceling of RCs may have been non-random, e.g. because protests may mainly arise in rural areas where households are more aware of the inflow of refugees. We therefore re-estimate the $K$-density, only when using the realized RCs. Figure B2 shows that realized RCs are a bit more dispersed, but still fall within the confidence bands.

density in drawing counterfactuals). The results of some of these exercises are available upon request. 


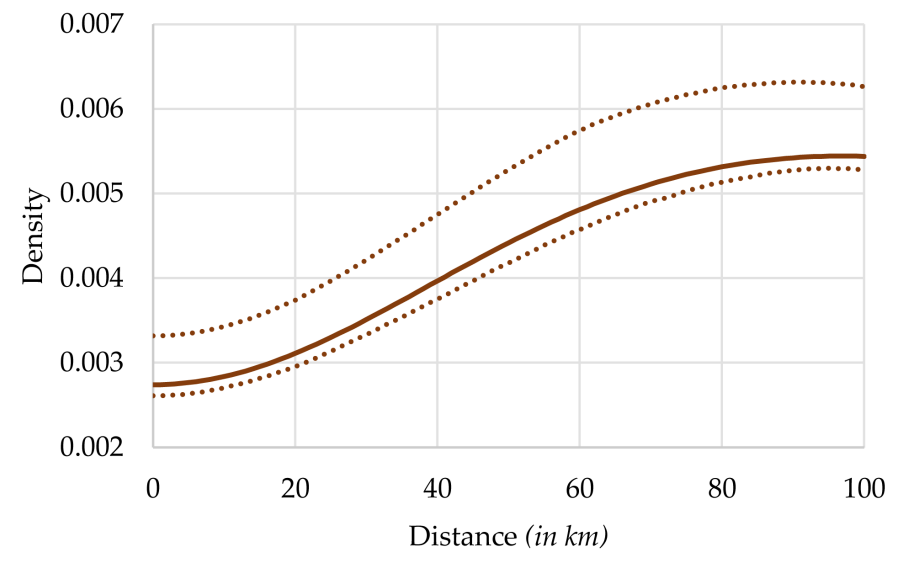

Figure B2 $-K$-DENSity For REALized RCs

Notes: The dotted lines represent respectively the lower and upper $5 \%$ global confidence band. 


\section{Online Appendix C}

C.1 More granular distance function

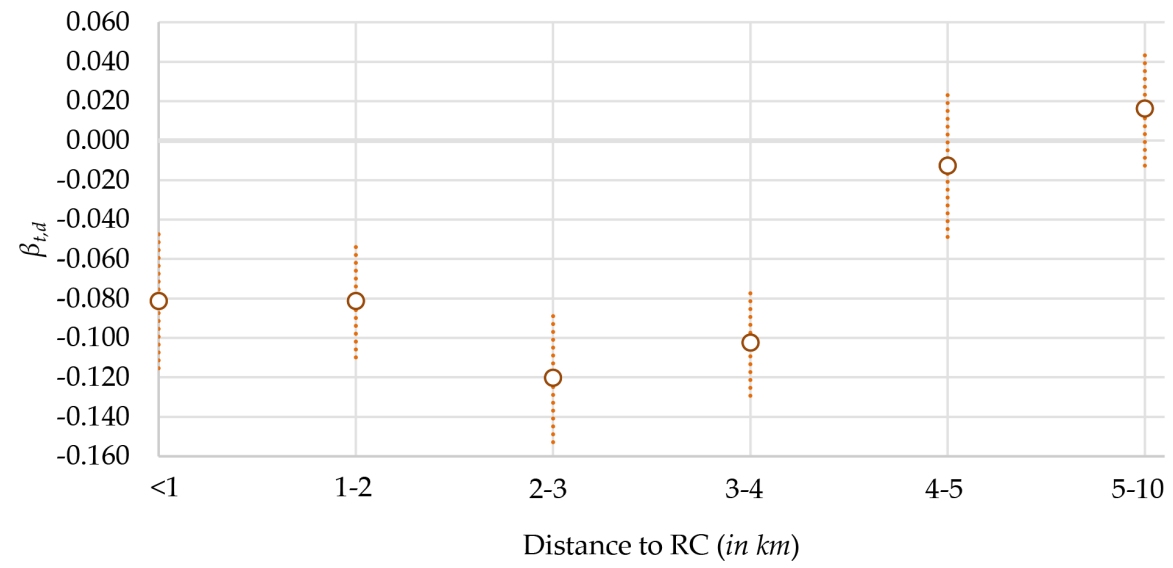

Figure C1 - Distance PRofile UP TO 10KM

Notes: The distance profile estimate reported in Table 4, column (5), is further decomposed over distance subcategories.

Figure $\mathrm{C} 1$ shows the effect using the variation in timing only, but now considering potential impact of RCs up to $10 \mathrm{~km}$. Interestingly, the effect seems to be negative and rather constant between $0-4 \mathrm{~km}$ from an $\mathrm{RC}$ and entirely disappears beyond $4 \mathrm{~km}$, which roughly corresponds to the size of municipalities in the Netherlands. 


\section{Online Appendix D}

\section{D.1 Heterogeneity in the effect: parametric estimation}

Having established the average effect, we further explore heterogeneity in the effect using the baseline version of equation (1), as reported in Table 4, column (3). In comparison to the nonparametric results we only focus on implicit prices and the role of refugee center characteristics and other potential determinants. That is, we add interaction terms between $\mathcal{R} \mathcal{C}_{i t}$ and whether the refugee center is located in a rural area (versus urban area), the capacity and relative (to the population) capacity, and whether the refugee center is located in a new building. The main issue with this estimation technique is that it does not necessarily account for sorting of individuals. The results are reported in Table D1. We focus the discussion on the final specification in column (6) which includes all of the interaction effects jointly.

First, we added the interaction effect with an indicator of a house being located in an urban or rural area as defined by Statistics Netherlands (also see Figure 4). We would expect that a larger refugee center has a larger impact in a small village in comparison to a large city. There is a negative coefficient on interaction term and it is marginally statistically significant. On top of the baseline effect of $-2.3 \%$, there is an additional negative effect of $-2.5 \%$ for rural areas.

Next, we added the interaction with a high capacity dummy ( $>500$ refugees), which is approximately equal to the average capacity in the sample. We also include an interaction with a high (above median) relative capacity indicator variable. The relative capacity is the capacity relative to the population within $2 \mathrm{~km}$ of the property. The results show that a relatively high capacity is associated with a decrease in price of $-2.7 \%$. The high relative capacity indicator is not statistically significant.

Finally, we added the interaction effect with a dummy indicating whether a refugee center is located in a new building. To control for the fact that this might just be reflecting (nuisance) as a result of new construction we control for the $(\log )$ number of new residential and commercial buildings constructed in the area. The results indicate that the effect of RCs opened in newly built buildings is -5.0 percentage points more negative, relative to RCs opened in existing buildings. 
TABle D1 - Interaction efFects: Refugee Center Characteristics (Dependent variable: the log of house price)

\begin{tabular}{|c|c|c|c|c|c|c|}
\hline & $\begin{array}{l}\text { (1) } \\
\text { Rural }\end{array}$ & $\begin{array}{c}(2) \\
\text { Capacity }\end{array}$ & $\begin{array}{c}\text { (3) } \\
\text { Relative capacity }\end{array}$ & $\begin{array}{c}(4) \\
\text { New built }\end{array}$ & $\begin{array}{c}(5) \\
+ \text { Extra controls }\end{array}$ & $\begin{array}{l}(6) \\
\text { All }\end{array}$ \\
\hline Refugee center opened & $\begin{array}{c}-0.0518^{* * *} \\
(0.0118)\end{array}$ & $\begin{array}{r}-0.0383^{*} \\
(0.0199)\end{array}$ & $\begin{array}{c}-0.0526^{* * *} \\
(0.0110)\end{array}$ & $\begin{array}{c}-0.0318^{* * *} \\
(0.0097)\end{array}$ & $\begin{array}{c}-0.0362^{* * *} \\
(0.0084)\end{array}$ & $\begin{array}{r}-0.0237^{*} \\
(0.0125)\end{array}$ \\
\hline $\begin{array}{l}\text { Refugee center opened } \times \\
\text { rural }\end{array}$ & $\begin{array}{l}-0.0255 \\
(0.0172)\end{array}$ & & & & & $\begin{array}{r}-0.0257^{*} \\
(0.0138)\end{array}$ \\
\hline $\begin{array}{l}\text { Refugee center opened } \times \\
\text { high capacity }\end{array}$ & & $\begin{array}{r}-0.0546^{*} \\
(0.0300)\end{array}$ & & & & $\begin{array}{c}-0.0276^{* *} \\
(0.0129)\end{array}$ \\
\hline $\begin{array}{l}\text { Refugee center opened } \times \\
\text { high relative capacity }\end{array}$ & & & $\begin{array}{l}-0.0136 \\
(0.0132)\end{array}$ & & & $\begin{array}{c}0.0028 \\
(0.0140)\end{array}$ \\
\hline $\begin{array}{l}\text { Refugee center opened } \times \\
\text { new built }\end{array}$ & & & & $\begin{array}{c}-0.0638^{* * *} \\
(0.0173)\end{array}$ & $\begin{array}{c}-0.0660^{* * *} \\
(0.0152)\end{array}$ & $\begin{array}{c}-0.0517^{* * *} \\
(0.0166)\end{array}$ \\
\hline New residential buildings (log) & & & & & $\begin{array}{c}0.0124^{* *} \\
(0.0056)\end{array}$ & $\begin{array}{c}0.0122^{* *} \\
(0.0056)\end{array}$ \\
\hline New commercial buildings (log) & & & & & $\begin{array}{c}-0.0087^{*} \\
(0.0051)\end{array}$ & $\begin{array}{l}-0.0082 \\
(0.0051)\end{array}$ \\
\hline Housing characteristics & Yes & Yes & Yes & Yes & Yes & Yes \\
\hline Postcode fixed effects & Yes & Yes & Yes & Yes & Yes & Yes \\
\hline Year and month fixed effects & Yes & Yes & Yes & Yes & Yes & Yes \\
\hline Observations & 194,436 & 194,436 & 166,031 & 194,436 & 194,436 & 194,436 \\
\hline$R^{2}$ & 0.93 & 0.93 & 0.92 & 0.93 & 0.93 & 0.93 \\
\hline
\end{tabular}

\section{D.2 Nonparametric estimation - first stage results}

We report the results of linear models for our sample including households characteristics in Table D2. When we rely on OLS, we find in column (1) that the average willingness to pay for refugee centers is $€ 16,011$. Given the average house price in the sample of $€ 228,837$, this means that the reduction in house prices is on average $7 \%$. We note that this is similar, albeit slightly higher, than the results using logs.

In column (2) we estimate the non-parametric regression. To determine the 'smoothness' of the non-parametric hedonic price function we use the cross-validation approach as outlined in equation 10. Figure D1 shows that the Root Mean-Squared Error is minimized when the bandwidth equals 1.914. Given this bandwidth we obtain the mean estimate reported in column (2). Looking at the standard error of the estimate, we find evidence for considerable heterogeneity in the willingness to pay for refugee centers. 
TABLE D2 - LINEAR AND NON-PARAMETRIC MODELS (Dependent variable: the log of house price)

\begin{tabular}{lcccc}
\hline \hline & $(1)$ & & $(2)$ \\
\cline { 2 - 2 } Refugee center opened, $<2 \mathrm{~km}$ & $-16,011^{* * *}$ & & $-18,239$ \\
& $(5,423)$ & & $(13,771)$ \\
& & & \\
Housing characteristics & Yes & & Yes \\
Postcode fixed effects & Yes & & Yes \\
Year and month fixed effects & Yes & & Yes \\
& & & \\
Observations & 57,728 & & 57,728 \\
$R^{2}$ & 0.9119 & \\
Bandwidth & $\infty$ & 1.914
\end{tabular}

Notes: We only include observations within $2 \mathrm{~km}$ of an RC. Bootstrapped standard errors are clustered at the neighborhood level and in parentheses. *** $\mathrm{p}<0.01$, ** $\mathrm{p}<0.05$, * $\mathrm{p}<0.1$.

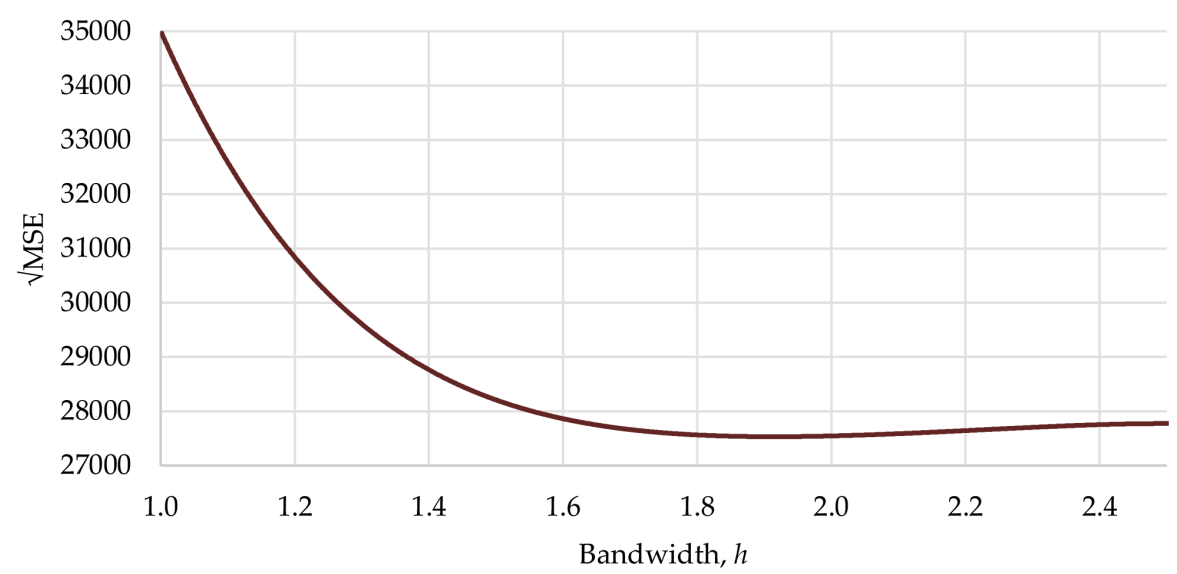

Figure D1 - ROOT MEAN-SQUARED ERROR FOR DIFFERENT BANDWIDTHS 


\section{Online Appendix E}

\section{E.1 Neighborhood level data on subjective well-being and unemployment}

We also examine the broader economic impact at a neighborhood level as an extension to the main analysis and to investigate whether those are in line with the effects on house prices. In particular, we collect additional data from the Dutch Housing Surveys (WoON) on (living) satisfaction, the intention to move (within two years), and more subjective indicators on nuisance and feelings of safety. We also have information about unemployment and the amount of hours worked and a wide range of housing attributes (e.g. the size of the property, house type and whether the household has moved within the last two years). We do not have information on actual crime rates. ${ }^{26}$ For each property in the survey we only know the location at the neighborhood level.

We combined five waves: 2002-2003, 2005-2006, 2008-2009, 2011-2012, and 2014-2015. Each wave consists of about 60,000 respondents and is considered to be a representative sample of the Dutch population. The descriptive statistics of the combined surveys are reported in Table E1. On average, about $7 \%$ of the respondents are dissatisfied with their neighborhood, $8 \%$ wants to move within two years, $5 \%$ experiences nuisances, and $8 \%$ feels unsafe. The average employment is $70 \%$ and the head of the household works about 48 hours a week. In only $2 \%$ of all cases a refugee center has been opened within $2 \mathrm{~km}$. We further added several household-specific variables such as yearly income, cultural background, and type of households as additional controls.

\section{E.2 Econometric framework}

We will estimate the same model as in equation (1) but at a neighborhood level and using a set of different dependent variables:

$$
y_{r k t}=\tilde{\beta} \mathcal{R} \mathcal{C}_{r k t}+\tilde{\gamma} x_{r k t}+\tilde{\lambda}_{k}+\tilde{\mu}_{t}+\tilde{\epsilon}_{r k t},
$$

where $y_{r k t}$ is the dependent variable of interest (e.g. satisfaction, nuisance) of a respondent $r$ living in neighborhood $k$ in year $t$. We emphasize that we cannot track individual respondents

\footnotetext{
${ }^{26} \mathrm{~A}$ detailed study on the effects of RCs on crime rates showed that there were no more crimes in close vicinity to RCs in comparison to other areas in the Netherlands (Achbari \& Leerkes 2017).
} 


\begin{tabular}{|c|c|c|c|c|}
\hline & $\begin{array}{c}(1) \\
\text { mean }\end{array}$ & $\begin{array}{c}(2) \\
\text { std.dev. }\end{array}$ & $\begin{array}{l}(3) \\
\min \end{array}$ & $\begin{array}{c}(4) \\
\max \end{array}$ \\
\hline Dissatisfied with neighborhood & 0.0696 & 0.255 & 0 & 1 \\
\hline Move & 0.0787 & 0.269 & 0 & 1 \\
\hline Nuisance & 0.0480 & 0.214 & 0 & 1 \\
\hline Unsafe & 0.0799 & 0.271 & 0 & 1 \\
\hline Unemployed & 0.692 & 0.448 & 0 & 1 \\
\hline Hours worked & 47.84 & 15.46 & 1 & 60 \\
\hline Refugee center opened, $<2 \mathrm{~km}$ & 0.0229 & 0.150 & 0 & 1 \\
\hline Gross yearly income & 42,398 & 51,375 & 0 & $1,753,644$ \\
\hline Age & 50.82 & 16.81 & 17 & 107 \\
\hline Foreign & 0.119 & 0.306 & 0 & 1 \\
\hline Single & 0.613 & 0.487 & 0 & 1 \\
\hline Kids & 0.349 & 0.477 & 0 & 1 \\
\hline Religion - christian & 0.457 & 0.498 & 0 & 1 \\
\hline Religion - muslim & 0.0389 & 0.193 & 0 & 1 \\
\hline Religion - other & 0.0618 & 0.241 & 0 & 1 \\
\hline \multicolumn{5}{|c|}{$\begin{array}{l}\text { Notes: We also include } 18 \text { housing characteristics, including house } \\
\text { type dummies, the floor of the apartment, the number of floors } \\
\text { in the building, whether the building has an elevator, whether } \\
\text { the property has central heating, a garage, the number of rooms } \\
\text { and construction decade dummies. The number of observations is } \\
285,031 \text {. }\end{array}$} \\
\hline
\end{tabular}

over time, implying that we cannot include respondent fixed effects. Furthermore, $\mathcal{R C}_{r k t}$ equals one when the centroid of a neighborhood is within $2 \mathrm{~km}$ of a refugee center (after opening), and $x_{r k t}$ are housing and household attributes.

We adopt the same identification strategies as outlined before. First, we use the whole sample. Second, we only include observations that are in a neighborhood with an RC or a planned/canceled RC. Third, we only exploit variation in timing implying that we include neighborhoods where there is an RC or will be one in the future (before 2015).

\section{E.3 Results}

Table E2 shows that the opening of an RC increases the probability of dissatisfaction in the neighborhood by about 1.4-2.0 percentage points, although this is not statistically significant at conventional levels in column (3), where we only rely on temporal variation in the opening of RCs. The effect is substantial given the sample mean of dissatisfaction of 0.0696. In addition, the opening of an RC increases the probability that households want to move within 2 years by 1.9-2.6 percentage points, which is statistically significant at the 5 or 10 percent level.

In Panel B of Table E2 we investigate whether households also experience more nuisance. We 
TABLE E2 - REGRESSION RESULTS: PERCEPTION AND EMPLOYMENT EFFECTS

\begin{tabular}{|c|c|c|c|c|c|c|}
\hline \multirow[t]{2}{*}{ Panel A: Satisfaction } & \multicolumn{3}{|c|}{ (Dep. var.: dissatisfied) } & \multicolumn{3}{|c|}{ (Dep. var.: intention to move) } \\
\hline & $\begin{array}{c}(1) \\
\text { OLS }\end{array}$ & $\begin{array}{c}(2) \\
\text { OLS }\end{array}$ & $\begin{array}{c}(3) \\
\text { OLS }\end{array}$ & $\begin{array}{c}(4) \\
\text { OLS }\end{array}$ & $\begin{array}{c}(5) \\
\text { OLS }\end{array}$ & $\begin{array}{c}(6) \\
\text { OLS }\end{array}$ \\
\hline Refugee centre in neighborhood & $\begin{array}{c}0.0170 * * * \\
(0.00646)\end{array}$ & $\begin{array}{c}0.0196 * * * \\
(0.00740)\end{array}$ & $\begin{array}{c}0.0139 \\
(0.00861)\end{array}$ & $\begin{array}{c}0.0188^{*} \\
(0.0109)\end{array}$ & $\begin{array}{c}0.0261^{* *} \\
(0.0113)\end{array}$ & $\begin{array}{c}0.0222^{*} \\
(0.0123)\end{array}$ \\
\hline Household characteristics (9) & Yes & Yes & Yes & Yes & Yes & Yes \\
\hline Housing attributes (16) & Yes & Yes & Yes & Yes & Yes & Yes \\
\hline Year fixed effects & Yes & Yes & Yes & Yes & Yes & Yes \\
\hline Neighbourhood fixed effects & Yes & Yes & Yes & Yes & Yes & Yes \\
\hline Number of observations & 282,229 & 27,270 & 13,798 & 282,229 & 27,270 & 13,798 \\
\hline$R^{2}$ & 0.064 & 0.058 & 0.069 & 0.090 & 0.098 & 0.106 \\
\hline \multirow[t]{2}{*}{ Panel B: Nuisance and safety } & \multicolumn{3}{|c|}{ (Dep. var.: nuisance) } & \multicolumn{3}{|c|}{ (Dep. var.: unsafe) } \\
\hline & $\begin{array}{c}(1) \\
\text { OLS }\end{array}$ & $\begin{array}{c}(2) \\
\text { OLS }\end{array}$ & $\begin{array}{c}(3) \\
\text { OLS }\end{array}$ & $\begin{array}{c}(4) \\
\text { OLS }\end{array}$ & $\begin{array}{c}(5) \\
\text { OLS }\end{array}$ & $\begin{array}{c}(6) \\
\text { OLS }\end{array}$ \\
\hline Refugee centre in neighborhood & $\begin{array}{c}0.0160^{* *} \\
(0.00715)\end{array}$ & $\begin{array}{c}0.0230 * * * \\
(0.00775)\end{array}$ & $\begin{array}{c}0.0214^{* *} \\
(0.00829)\end{array}$ & $\begin{array}{c}0.00539 \\
(0.00920)\end{array}$ & $\begin{array}{c}0.00924 \\
(0.00986)\end{array}$ & $\begin{array}{c}0.00566 \\
(0.0106)\end{array}$ \\
\hline Household characteristics (9) & Yes & Yes & Yes & Yes & Yes & Yes \\
\hline Housing attributes (16) & Yes & Yes & Yes & Yes & Yes & Yes \\
\hline Year fixed effects & Yes & Yes & Yes & Yes & Yes & Yes \\
\hline Neighbourhood fixed effects & Yes & Yes & Yes & Yes & Yes & Yes \\
\hline Number of observations & 282,229 & 27,270 & 13,798 & 282,229 & 27,270 & 13,798 \\
\hline$R^{2}$ & 0.045 & 0.045 & 0.049 & 0.081 & 0.079 & 0.089 \\
\hline \multirow[t]{2}{*}{ Panel C: Employment } & \multicolumn{3}{|c|}{ (Dep. var.: unemployment) } & \multicolumn{3}{|c|}{ (Dep. var.: hours worked) } \\
\hline & $\begin{array}{c}(1) \\
\text { OLS }\end{array}$ & $\begin{array}{c}(2) \\
\text { OLS }\end{array}$ & $\begin{array}{c}(3) \\
\text { OLS }\end{array}$ & $\begin{array}{c}(4) \\
\text { OLS }\end{array}$ & $\begin{array}{c}(5) \\
\text { OLS }\end{array}$ & $\begin{array}{c}(6) \\
\text { OLS }\end{array}$ \\
\hline Refugee centre in neighborhood & $\begin{array}{c}-0.0383^{* *} \\
(0.0170)\end{array}$ & $\begin{array}{c}-0.0368^{* *} \\
(0.0181)\end{array}$ & $\begin{array}{c}-0.0387^{* *} \\
(0.0184)\end{array}$ & $\begin{array}{c}-0.347 \\
(0.858)\end{array}$ & $\begin{array}{l}-0.345 \\
(0.864)\end{array}$ & $\begin{array}{c}-0.233 \\
(0.876)\end{array}$ \\
\hline Household characteristics (9) & Yes & Yes & Yes & Yes & Yes & Yes \\
\hline Housing attributes (16) & Yes & Yes & Yes & Yes & Yes & Yes \\
\hline Year fixed effects & Yes & Yes & Yes & Yes & Yes & Yes \\
\hline Neighbourhood fixed effects & Yes & Yes & Yes & Yes & Yes & Yes \\
\hline Number of observations & 282,229 & 27,270 & 13,798 & 282,229 & 27,270 & 13,798 \\
\hline$R^{2}$ & 0.437 & 0.427 & 0.430 & 0.375 & 0.375 & 0.376 \\
\hline
\end{tabular}

find that the probability increases by 1.6-2.3 percentage points after an RC has been opened. There does not seem to be an increase in the feeling of unsafety, which is in line with the previous literature that does not find effects on local crime rates (see Achbari \& Leerkes 2017).

Finally, in Panel $\mathrm{C}$, the opening of an $\mathrm{RC}$ seems to reduce local unemployment, but it does not increase the number of hours worked. This apparent discrepancy has to do with the definition of unemployment. If a respondent already works for 2 hours, he or she is no longer considered 
unemployed. This suggests that RCs particularly create small/part-time employment effects. ${ }^{27}$ Despite small positive employment effects, the effect of nuisance seems to dominate the effects of RCs on local communities, given that the average effects of RCs on house prices (and satisfaction and intention to stay) is negative.

\footnotetext{
${ }^{27}$ In addition, there may be effects outside of the local neighborhood: it is well known (i.e. reported by COA) that there may be many (also non-local) people working in an $\mathrm{RC}$, which is something we do not directly measure.
} 